\title{
Extensive analysis of photovoltaic battery self-consumption: Evaluation through an innovative district case-study ${ }^{\circledR}$
}

Cite as: Appl. Phys. Rev. 6, 021301 (2019); https://doi.org/10.1063/1.5049665

Submitted: 24 July 2018 . Accepted: 08 March 2019 . Published Online: 04 April 2019

L. Millet (D), A. Berrueta (D), M. Bruch (D), N. Reiners (D), and M. Vetter (i)

\section{COLLECTIONS}

EP This paper was selected as an Editor's Pick
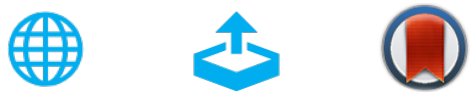

\section{ARTICLES YOU MAY BE INTERESTED IN}

Conformality in atomic layer deposition: Current status overview of analysis and modelling Applied Physics Reviews 6, 021302 (2019); https://doi.org/10.1063/1.5060967

From thermoelectricity to phonoelectricity

Applied Physics Reviews 6, 021305 (2019); https://doi.org/10.1063/1.5031425

Radiative sky cooling: Fundamental principles, materials, and applications

Applied Physics Reviews 6, 021306 (2019); https://doi.org/10.1063/1.5087281

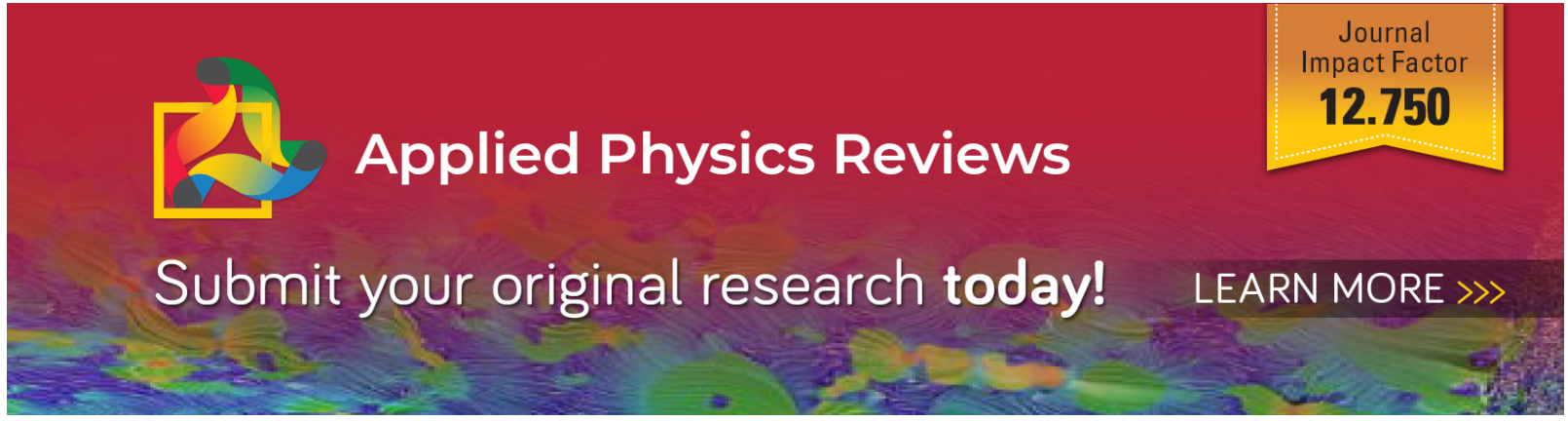




\title{
Extensive analysis of photovoltaic battery self-consumption: Evaluation through an innovative district case-study ${ }^{\circ}$
}

Cite as: Appl. Phys. Rev. 6, 021301 (2019); doi: 10.1063/1.5049665

Submitted: 24 July 2018 - Accepted: 8 March 2019 .

Published Online: 4 April 2019

L. Millet, ${ }^{1}$ (D) A. Berrueta, ${ }^{2}$ (D M. Bruch, ${ }^{1}$ (D N. Reiners, ${ }^{1}$ (iD and M. Vetter ${ }^{\top}$ iD

\begin{abstract}
AFFILIATIONS
${ }^{7}$ Fraunhofer Institute for Solar Energy Systems ISE, Department Electrical Energy Storage, Heidenhofstraße 2, 79110 Freiburg, Germany

${ }^{2}$ Institute of Smart Cities, Public University of Navarre, Campus de Arrosadía, 31006 Pamplona, Spain
\end{abstract}

\begin{abstract}
Energy storage is one of the key elements within the actual stage of the energy transition, as it is probably one of the most important factors to allow high penetration of fluctuating renewable energies, such as wind or solar, in the existing power systems. Intensive research is being conducted to assess the economic aspects and technical performance of renewable energy-based systems supported by batteries by evaluating different services that batteries can provide to the electric grid or to the end-consumers. In Germany, where the majority of the currently installed $43 \mathrm{GW}$ of PV capacity corresponds to small residential, commercial, or industrial facilities, an interesting market for batteries to enhance local self-consumption and autarky is already booming, with more than 80000 storage system installations in 2017. In this context, this study presents a comprehensive analysis of the photovoltaic battery model by analyzing the technical and economic consequences that variations on the most relevant system parameters induce. The presented results are based on high resolution data obtained from a representative residential district with an autarky of above 95\%. The employed battery model is based on the results obtained through an extensive test campaign and includes electrical and thermal sub-models. The analysis predicts that grid parity of residential PV battery systems can be reached in the upcoming years, with especially great potential of the retrofitting market for those PV installations which run out of the feed-in tariff policy.
\end{abstract}

Published under license by AIP Publishing. https://doi.org/10.1063/1.5049665

\section{TABLE OF CONTENTS}

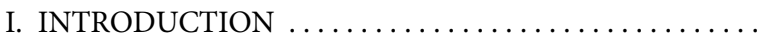

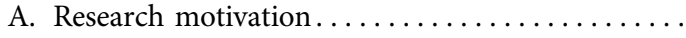

B. The self-consumption model in Germany .......

C. Related work and scope of this study ..........

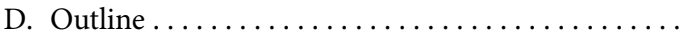

II. CASE STUDY $\ldots \ldots \ldots \ldots \ldots \ldots \ldots \ldots \ldots \ldots \ldots \ldots \ldots \ldots$

III. SYSTEM MODELLING $\ldots \ldots \ldots \ldots \ldots \ldots \ldots \ldots \ldots$

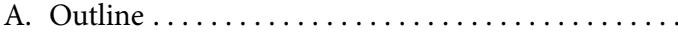

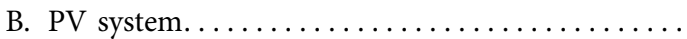

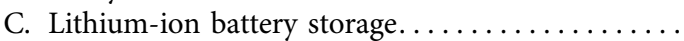

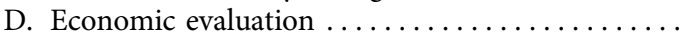

E. Model convergence: Influence of the time-step

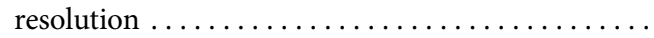

IV. ANALYSIS OF THE SELF-CONSUMPTION MODEL

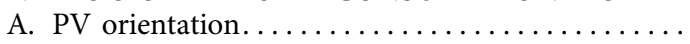

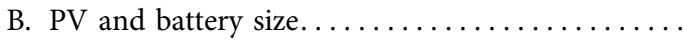

C. Size of power converters ................. 10

D. PV and battery degradation ................. 10 V. RETROFITTING MARKET POTENTIAL . ......... 12 VI. CONCLUSIONS......................... 13

\section{INTRODUCTION}

Wind power and photovoltaics are, in actuality, the lowest cost technologies to generate electricity from renewable sources. Therefore, its worldwide installed capacity resembles exponential growth. To give an example, it can be highlighted that more than $25 \mathrm{GW}$ of new wind and PV capacity were commissioned in Europe in 2017 , rising in sum to more than $75 \%$ of newly installed capacity. ${ }^{2}$ However, increasing shares of these highly fluctuating power sources require system flexibility solutions, such as grid extension measures and supply- or demand-side management to ensure grid stability and reliability. 
Different stationary storage technologies can be adopted to shift energy on the short, mid, and long-term to adequate the energy production to its consumption and thus provide flexibility from the supply-side (before-the-meter systems) or the demand-side (behindthe-meter applications) management. However, the integration of energy storage systems is still most likely not economically viable for a large-scale market uptake, since, with actual battery prices, calculated payback periods are most often longer than the expected operating life. ${ }^{4}$

\section{A. Research motivation}

PV battery systems are expected to drive the market development of decentralized power generation and increased self-sufficiency ${ }^{5}$ in order to accomplish with the objectives defined under the Energy Performance of Buildings Directive, which requires all new buildings to approach a net zero energy balance (NZEB) by 2020.

When integrated with small to middle size PV appliances, installed in industrial, commercial, or residential rooftops, battery storage systems open the window to some interesting revenue schemes, such as energy arbitrage, to take profit of variable electricity pricing such as time-of-use (TOU) or real-time pricing (RTP) tariffs; peak shaving, to reduce capacity tariffs; or supply management, e.g., to increase self-consumption.

Even though similar to the case of PV systems-whose adoption is still tied to subsidies in form of feed-in tariffs, green certificates, or favorable net metering schemes ${ }^{9,10}$ - the profitability of storage systems is, in general, subject to the available subsidies that promote their adoption.

Being the residential self-consumption and the landlord-to-tenant electricity supply models an active research topic, this work aims to contribute to the research community by providing a detailed economic and technical evaluation of an exemplary PV battery system based on high-resolution monitoring data of a middle-size residential district.

\section{B. The self-consumption model in Germany}

Both the PV self-consumption and the adoption of battery storage are currently allowed in the vast majority of world countries. However, and as explained in detail in Ref. 11, there are many and very different approaches to its regulation. For this reason, a general economic assessment is not feasible, and its evaluation needs to be subject to a particular market or case study.

In this case, the study focuses on the German market, where behind-the-meter, battery applications have particularly high market potential because of the following two main reasons:

- According to the data published by the Federal Network Agency in Germany, a great portion of the approximately $43 \mathrm{GW}$ of already installed PV capacity corresponds to small or medium, residential, industrial, or commercial installations.

- Almost $90 \%$ of the population supports the energy transition and the aim to decarbonize the energy sector and up to $75 \%$ are willing to take active part in the process, as depicted by a recent survey from the Potsdam Institute for Advanced Sustainable Studies. ${ }^{12}$

The self-consumption framework places consumers at the core of the energy transition and is publicly promoted and supported by the European Commission. ${ }^{13}$ Besides, the German regulatory framework pushes the adoption of battery storage through indirect incentives including discounts in the applicable energy taxes ${ }^{14}$ and cheaper power prices for more autarkical tenants. ${ }^{15}$ Landlord-to-tenant electricity supply models, which, e.g., allow for the adoption of district storage systems, are also exempt from a wide range of charges that they would otherwise have to pay if they purchased their electricity via the grid. ${ }^{14,16}$ In parallel, the major support is provided through the financing program 275 of the KfW credit institute.

Although profitability of battery adoption for such use-cases is not proved yet, over 80000 PV battery systems were installed in Germany in 2017, reaching a quote of up to $50 \%$ of the total newly installed PV home systems, ${ }^{17}$ proving that the uptake of PV battery systems will not necessarily be exclusively driven by exogenous factors, such as the system costs, but also by endogenous factors such as consumers' value of self-sufficiency, their degree of environmental concern, or their interest in innovative technologies. ${ }^{18,19}$

Related to the first reason above, and as the PV capacity installation boomed between 2009 and 2013, the analysis of this paper includes a more specific analysis (in Sec. V) on the opportunity gap that provides the so-called "retrofitting market". This business case includes those PV systems which, in the near future, will have covered the 20 -year subsidy and will thus stop receiving the feed-in tariff for the energy delivered to the grid.

\section{Related work and scope of this study}

Detailed reviews on published studies quantifying different residential use-cases of increased PV self-consumption by the adoption of battery storage and/or by the implementation of demand-side management (DSM) strategies can be found in Refs. 19 and 20. These reviews can be complemented with more recent studies, such as the one presented by Naumann et al., ${ }^{21}$ which includes multi-period simulation and prognosticates PV battery systems to reach grid parity in Germany as of 2018 , or with the investigation by Merei et al., ${ }^{22}$ which foresees economic profit of battery storage as of 2025 for commercial applications. Nonetheless, most of the studies conclude that battery prices still need to fall to create a business case out of the selfconsumption model, even if optimization strategies for battery dispatch for different electricity markets and regulations are included in the models as given in Refs. 23-25.

Our contribution, analogous to the above-mentioned work, analyzes the technical and economic characteristics of the PV battery model for enhanced self-consumption under a novel application: a district model with a central storage and a distributed building-integrated PV installation. Related to similar models with storage and distributed renewable sources, interesting studies present optimal power flow (OPF) simulations to analyze the bottlenecks and limitations of net zero energy building communities ${ }^{26}$ or to evaluate the differences between central and distributed battery storage units. ${ }^{27}$ However, the spatial distribution of the power system and network design is beyond the scope of this study, which seeks to focus on the sizing of the system components and the economic evaluation.

The quality of the experimental data employed in this study is the most differentiating factors with respect to the existing literature. On the one hand, the used monitoring data, obtained at a 1-s rate, are of higher time resolution than that shown in the majority of related studies. On the other hand, we present a high-accurate battery model, based on the results of an extensive test campaign, which is only 


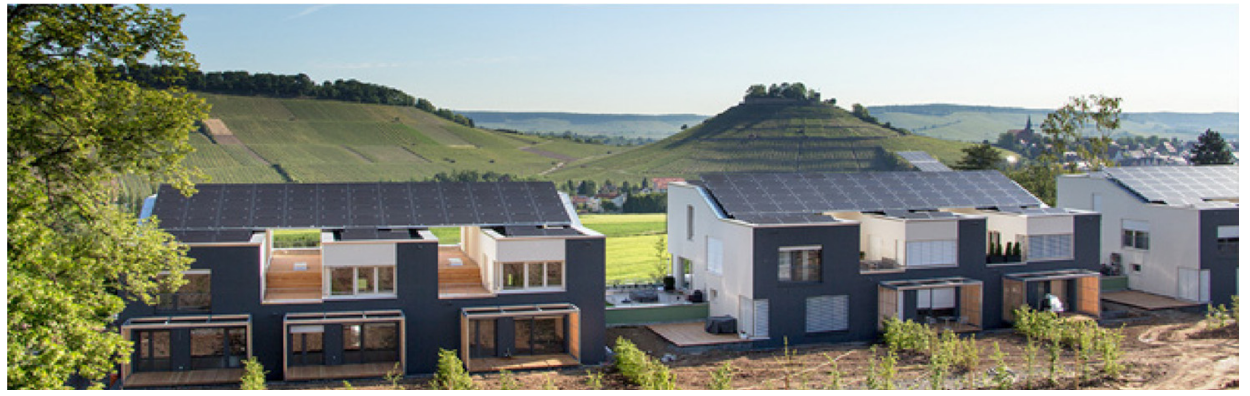

FIG. 1. Picture of the residential neighborhood in Weinsberg, Germany. The combination of PV modules, a CHP engine, and energy storage systems allows a high level of self-sufficiency in the energy consumption of the neighborhood. Reproduced with permission from DSG Holding $\mathrm{GmbH}$ \& Co. KG.

comparable to few previous studies, such as Refs. 28 and 7. Our work evaluates in detail the effects of time-step, component degradation, end-of-life prediction, and power-to-capacity ratios on the performance and economic value of the system, seeking, hence, to present a very complete analysis on the most important design parameters that affect the techno-economic evaluation of similar self-consumption models in residential districts.

\section{Outline}

This paper is divided into 6 sections. After the introduction, Sec. II describes the reference case-study project, where the power supply system is explained, and the load consumption data are analyzed. Section III includes the description of the employed simulation model. In Sec. IV, the results corresponding to a number of simulations with varying variables-parametric sweep-are shown, in order to give insight into the effect of the most relevant design variables for a PV-battery system. In Sec. V, the market potential for the diffusion for such a model is discussed, and a prediction of market evolution of the PV-battery system is presented, emphasizing the retrofitting case study. Finally, the major findings and the conclusions are gathered in Sec. VI.

\section{CASE STUDY}

The reference case study presented in this paper corresponds to a medium-size, net zero energy residential district located in the German town of Weinsberg (see Fig. 1). Along with the project developer Kruck + Partner, the Fraunhofer ISE collaborated in the development of the innovative energy concept, the optimal sizing and selection of the power supply system components, and the energy management strategies.

Most of the electricity and heating demands of this neighborhood, which was commissioned as of 2013 and comprises 23 households, are covered by local power sources. In Fig. 2(a), the schematic drawing of the electrical and the thermal energy system of the district is presented. Solar PV is the main power source, with an installed capacity of $145 \mathrm{kWp}$ mounted on the building rooftops. When there is an excess PV power production, dispatch management operates an air-to-water heat pump to heat water, thereby increasing the direct self-consumption. Furthermore, when there is a deficit of solar resource, a cogeneration unit with a rated power of $11 \mathrm{~kW}_{\mathrm{el}} / 27 \mathrm{~kW}_{\mathrm{th}}$ is used in order to cover both electrical and thermal demands. Both centralized and distributed energy storage systems are key elements for the management, system integration, and for an increased selfsufficiency of this district. The centralized energy storage consists of a $150 \mathrm{kWh}$ lithium-ion battery and a $20000 \mathrm{~L}$ tank of warm water; while a set of distributed thermal storage tanks have also been installed at the residential buildings. During the first year of operation of this system, a self-sufficiency above $90 \%$ and a self-consumption above $85 \%$ were reported via a quality monitoring program, even though a few operation stops were recorded, and updates in the energy management system (EMS) were needed.

The Weinsberg neighborhood is chosen as a reference project for this study due to the interest of its social and energetic model for efficient decentralized self-consumption and self-sufficiency. Moreover, the combined analysis of electricity and heating demand has increasing interest for the decarbonization of the heating systems. The aim of this paper is to analyze the viability of a general business case: the addition of an energy storage system to an existing or new photovoltaic installation. With this purpose, the real electrical and thermal data recorded form Weinsberg are used for model validation. In this study, only the electrical power system was investigated, including the PV generator, the battery storage, and the electrical load. The analysis of the thermal system is not part of this paper and is still under investigation.

After installation of the power supply system, a monitoring campaign was conducted at this residential nucleus in order to validate the correct functioning of all components and to optimize the operating control strategy algorithms of the energy management. As depicted in Fig. 2, six different monitoring devices were deployed to measure the energy flow of each of the power system components separately. The sampling frequency for readings was $1 \mathrm{~s}$, and the monitoring was performed within a period of one year.

The daily load profile is presented in the form of a boxplot in Fig. 3 , showing the median and the quartiles distribution of the data

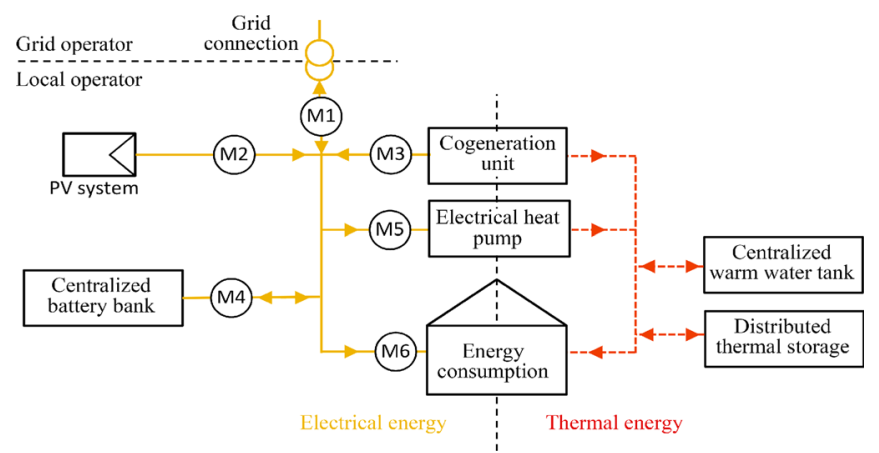

FIG. 2. Scheme of the power and heat supply system and installed electrical metering points (M1 to M6) at the case study district in Weinsberg. 


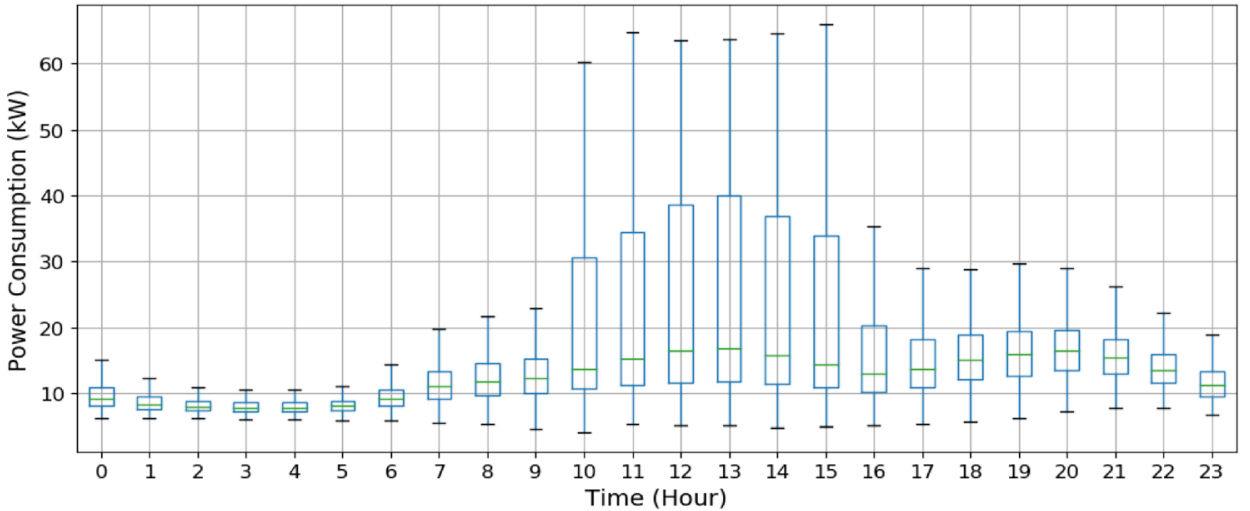

FIG. 3. Boxplot of the average electrical power consumption distribution throughout the hour of the day. In this plot, the boxes show the quartiles Q1, median (Q2), and Q3 of the data, while whiskers are limited by extreme data measurements or 1.5 times the interquartile range $(I Q R)$.

corresponding to the whole year. Especially noteworthy is the difference between the power consumption during the night hours $(8 \mathrm{~kW}$ of median power in the whole district during the studied year) and that of peak hours, around noon, reaching a median of $17 \mathrm{~kW}$. It is also relevant to note that the minimum dispersion between different days along the year takes place during night hours, while the maximum dispersion is measured around noon and can be attributed to the operation of the electrical heat pump. As explained, the heat pump is mainly operated only when there is excessive PV generation, and from the monitoring campaign, the heat pump is observed to represent about $1 / 3$ of the annual electrical consumption. Thus, in this neighborhood, around $1 / 3$ of the total load is subject to demand-side management (DSM). Even though the average power consumption during the afternoon and evening is high, the measured dispersion during this period is lower than the one measured around noon.

The energy that is consumed by the heat pump has been omitted for the simulations presented in Secs. IV and V. The reason is that such complex dispatch management as the installed in this pilot project is not common in other residential districts. Hence, the analysis is valid to represent a larger number of districts with similarly high PV share.

Regarding the annual consumption, average values are more informative than the median, given that the calculation of the monthly or annual energy consumption is trivial from the average power. The average power consumption during the year is $15.12 \mathrm{~kW}$, which leads to an average energy consumption of $132 \mathrm{MWh} /$ year and corresponds to about $4200 \mathrm{kWh} /$ year per household.

\section{SYSTEM MODELLING}

The adoption of PV battery systems requires facing a high investment front. Therefore, detailed simulation-based analyses and independent consulting services are vital for ensuring the bankability, investability, and insurability needed for the realization of such projects. Linked to the increasing interest of residential PV systems, many software tools have been commercially launched within the last decade to estimate the photovoltaic power generation, such as PVsyst, PV FChart, pvPlanner, PVsol, RETscreen, or SolarPro. ${ }^{29}$

Similarly, many other programs have appeared with the objective of facilitating the technical design of Hybrid Renewable Energy Systems (HRESs) and to assess the decision making process in their attributed investments, such as the System Advisor Model (SAM) or HOMER. However, these software tools have important limitations and do not usually offer sufficient flexibility for evaluating some important study parameters, such as simulation time-step or battery aging.

The simulation model is not the main focus of this paper but the implications of the self-consumption model and their dependencies with respect to the main design variables. Therefore, a simplified description of the employed model for PV and battery components is included in this section, emphasizing the assumed model constraints and simplifications. The costs assumed for the components are presented in detail, together with detailed forecasts of their price reduction over time, based on the expected market evolution. In the last part, the model convergence and accuracy are evaluated with respect to the data granularity.

\section{A. Outline}

A conceptual flow diagram describing the system model presented in this paper is shown in Fig. 4. It contains information about the employed energy management strategy, which maximizes selfconsumption, and about the data sources and degrees of freedom that the simulation solves for.

It can be observed that if PV production exceeds the instantaneous load consumption, the first priority is to charge the battery (Prio $2 a$ ). Thus, the PV overproduction is only fed into the grid once the battery is fully charged (Prio 3a). Similarly, when there is not enough

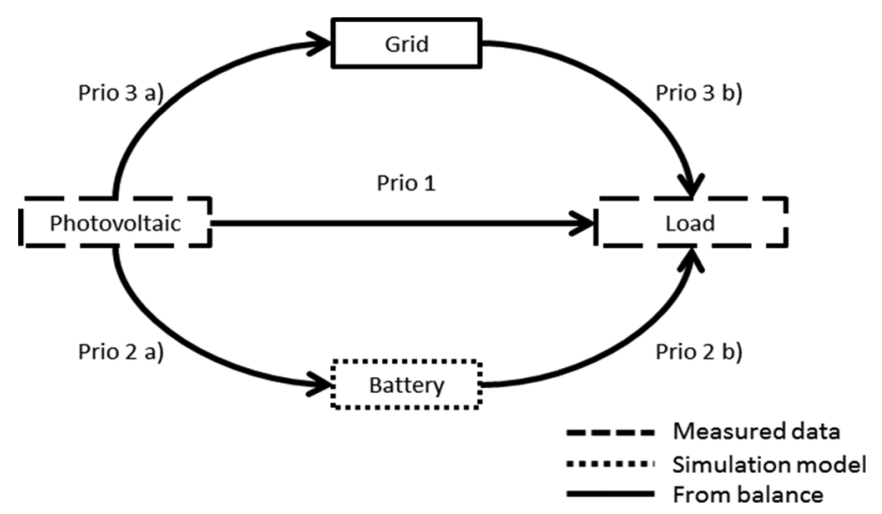

FIG. 4. Conceptual flow diagram of the dispatching model used for the simulation of the investigated district. 
solar generation, the energy is taken in priority from the battery (Prio $2 b$ ) and, only if the storage is empty, from the grid (Prio 3b).

As shown in Fig. 4, the high-resolution monitored data from the installed PV systems and the consumption in the Weinsberg district are used as input values for the simulation in Secs. IV and V, unless the contrary is specified. The battery model is the core element of the simulation, and its performance determines the energy balance with the grid.

\section{B. PV system}

As mentioned above, the standard model used in this paper does not include a PV-simulation but incorporates the high-resolution measurement data as a time-series model input. However, one part of the analysis in this work is to investigate the influence of the module orientation on the indicators of interest (see Sec. IV A).

For that analysis, exclusively, a PV-simulation model was employed and fitted, or calibrated, to replicate with sufficient accuracy the monitoring data. Within Sec. IV A, the conversion of solar irradiance to electric power is modelled using the PV-LIB toolbox, a set of open-source state-of-the-art modelling functions for simulating the performance of photovoltaic energy systems developed by Sandia National Laboratories. ${ }^{30}$ To perform the simulation, PV-LIB calculates the relative position of the sun and, using horizontal irradiance data and an atmosphere model, divides this global irradiance into its direct and diffuse components. With these variables and the ambient temperature, the module orientation and array size, the PV cell temperature, and I-V characteristics are calculated. The DC to AC conversion within the solar inverter is modelled through the Driesse model, ${ }^{31}$ which takes into account power and input voltage in the calculation of inverter efficiency. For the weather resources, TMY3 data from a close weather station to the location of the project were used.

Within the rest of the analysis, the use of the monitoring data is preferred due to its high temporal resolution, as a thinner granularity than $1 \mathrm{~min}$ sampling is generally not available for weather data.

\section{Lithium-ion battery storage}

The most important factors affecting the lifetime and performance of lithium-ion batteries are known to be the operating temperature, the state of charge, and the operating current rates. Therefore, evaluating the profitability of adopting a lithium-ion battery calls for a detailed inclusion of the battery sensitivity to those parameters in the simulation. Most of the models found in the literature do not include implicit dependencies on those factors and assume a fixed number of cycles or hours of lifetime. Only a very few examples, such as the work of Uddin et al., ${ }^{28}$ have been found including battery models based on experimental characterization procedures for analyzing residential behind-the-meter PV battery applications.

In this paper, the electrical model of the battery system, implemented in Matlab, is based on an equivalent-circuit model of a lithium-ion pouch battery cell with lithium iron phosphate $\left(\mathrm{LiFePO}_{4}\right)$ as a cathode material and graphite as an anode material, and the parameters of which were characterized in the laboratory of Fraunhofer ISE through an extensive test campaign. To increase readability, the experimental results that confirm the reference look-up tables for the employed battery model are gathered in Appendix A. Similarly, the flowchart showing the logical procedure followed by the battery model to iterate through the time-series simulation is not included within the body of the paper but in Appendix B.

The state of charge of the battery is calculated by the so-called coulomb counting method by

$$
\operatorname{SOC}\left(t_{2}\right)-\operatorname{SOC}\left(t_{1}\right)=\frac{\int_{t_{1}}^{t_{2}} I(t) \cdot d t}{C_{n o m}(t)} .
$$

A single internal resistance is considered within the equivalent circuit model to account for battery efficiency and to determine operating voltage and represents different electric and electrochemical effects altogether. Thus, the battery voltage is computed at every battery cell by

$$
V=I \cdot R_{\text {int }}+ \begin{cases}U_{O C V, \text { discharge }}, & I<0 \\ U_{O C V, \text { charge }}, & I \geq 0,\end{cases}
$$

where the current for each battery cell is obtained by dividing the total battery pack current by the total number of parallel stacks. As detailed in Appendix A, the single internal impedance, $R_{\text {int }}$, is parametrized as a function of operating current rate, states of charge (SOC), and temperature.

As the temperature greatly affects performance and degradation of the battery, the employed battery model incorporates a thermal sub-model. The volumetric battery heat generation is characterized by the well-known expression ${ }^{32}$

$$
\dot{q}_{g e n}=I^{2} R_{i n t}+I T \frac{d U}{d T},
$$

where the first term corresponds to the irreversible, or Joule heat losses, and the second to the reversible or entropic losses. The thermal interaction of the battery and the ambient temperature is modelled through a simplified thermal conductance, $k$, which models both natural convection and heat conduction through the battery stack. Besides, simple active cooling/heating strategies are implemented to stand for the thermal management system, consisting of a forced convection system with a fixed coefficient of performance (COP). The active cooling is triggered in the simulation when battery temperature exceeds the user-defined acceptable operating range. Thus, the thermal energy balance remains

$$
m C_{P} \frac{d T}{d t}=\left(\dot{q}_{\text {gen }}-\dot{q}_{\text {active }}\right)-k A\left(T-T_{\infty}\right),
$$

where the magnitude of active cooling/heating, $\dot{q}_{\text {active }}$, can be regulated by the constant $c_{1}$

$$
\dot{q}_{\text {active }}=c_{1} \cdot\left(T-T_{\text {limit }}\right),
$$

and its electrical consumption, affecting the efficiency of the battery pack, is computed by

$$
P_{\text {cooling }}=\frac{\dot{q}_{\text {cooling }}}{C O P}
$$

\section{Economic evaluation}

The economics of the self-consumption PV battery model is mainly evaluated in this paper through the levelized cost of consumed electricity (LCOE) as the main indicator. This is defined as the average 
cost per kWh of useful electrical energy consumed by the system during the whole project's lifetime and is computed as

$$
L C O E=\frac{N P V}{\sum_{t=1}^{n} \frac{E_{t}}{(1+d+e)^{t}}}
$$

with

$$
N P V=\sum_{t=1}^{n} \frac{\text { CAPEX }_{t}+\mathrm{OPEX}_{t}}{(1+d)^{t}},
$$

where $E_{t}$ is the energy consumed at each time period, the project horizon is $n, e$ is a derating rate, and $d$ is the real discount rate, which reflects the time-value of money, or opportunity costs, plus the inflationary effects.

For a correct estimation of capital expenditures (CAPEX) related to PV and battery system components, the size of the power plant or storage system plays a major role. In this paper, the effects of the size of the components on their purchase price have been estimated from an average of the data collected from our previous projects and supplemented with the information in Refs. 33 and 34 for the PV components and from the data provided in Ref. 35 for the battery system, as shown in Fig. 5. Then, price vs. size curves are interpolated in the model to compute initial capital.

For OPEX and for the replacement CAPEX, however, the effect of the technology price experience curve should also be accounted for, as it
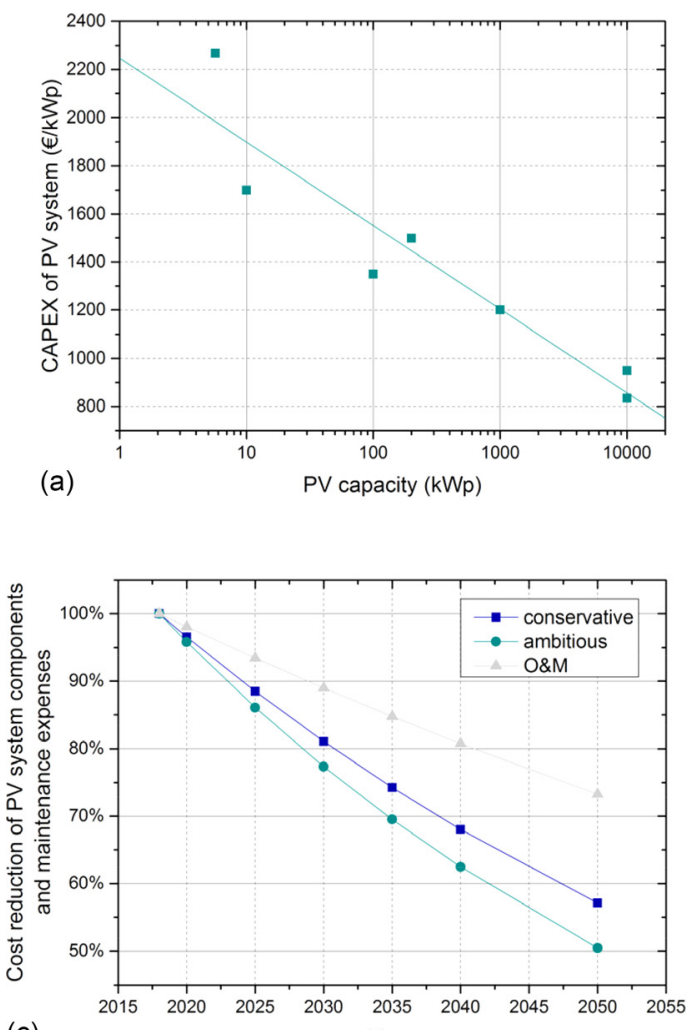

(c) Year can be foreseen that PV and battery system components cost will keep decreasing considerably in the short- and mid-term, as the cumulated world manufacturing capacity keeps increasing. The learning rate for PV technologies, including module manufacturing, installation, O\&M, and other related activities, is considered approximately $18 \%-22 \%$, as described in the detailed forecasts published by Mayer et al. ${ }^{36}$ The evolution of the battery market and the global manufacturing capacity increase is much more uncertain and very much linked to the adoption of electrical vehicles (xEVs). In this paper, data provided in Refs. 37 and 38 were adopted, and with a learning rate of $15-19 \%$, the price of lithium-ion battery cells is predicted to decrease about $60 \%$ by 2030 .

For excess PV power fed into the public grid, the 2018 feed-in tariff (FIT), set by the Renewable Energy Sources Act (EEG) in Germany, has been selected. This corresponds to a value of $\sim 8.5 \mathrm{ct} € /$ $\mathrm{kWh}$ for solar installations between 10 and $750 \mathrm{kWp}$. The electricity tariff for the district households is set to $30 \mathrm{ct} € / \mathrm{kWh}$. Note that the difference or margin between the feed-in and the grid tariffs is the main economical driving factor for enhancing the self-consumption and thus reducing consumers' final costs of electrical energy.

In order to obtain the LCOE, the considered project horizon is of 25 years, and the salvage value of any of the system components whose useful life extends to a further horizon is accounted for the LCOE calculations as

$$
\text { Salvage }=\text { CAPEX }_{\text {replacement }} \cdot\left(\frac{\text { Years Left }}{\text { Total Life }}\right) .
$$
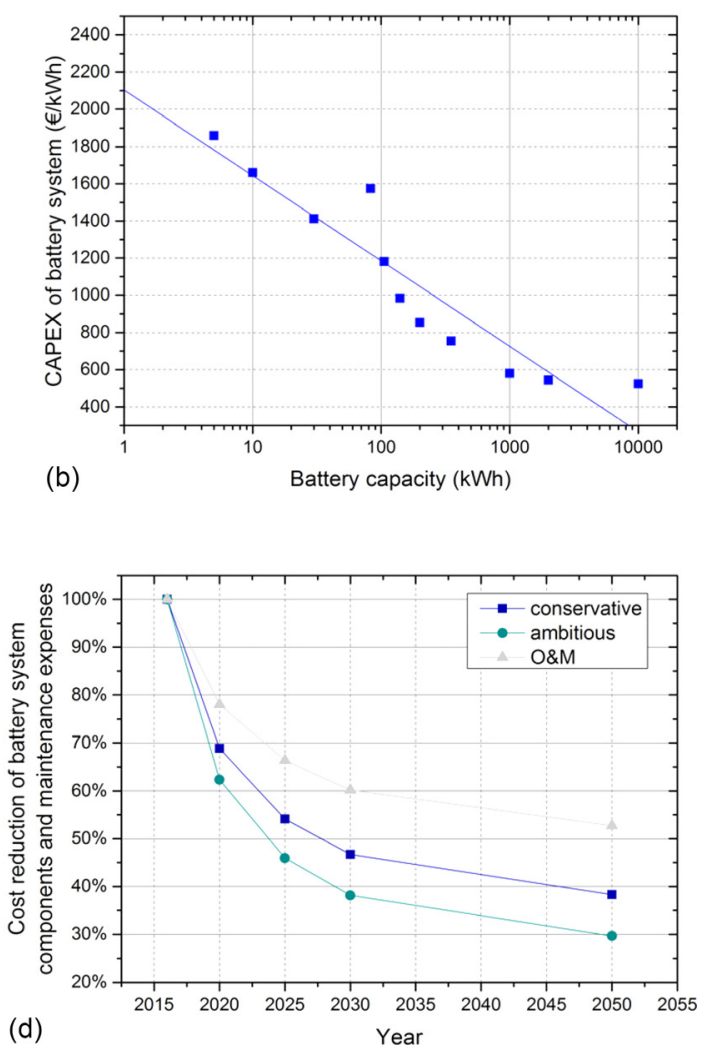

(d)

FIG. 5. Cost of PV and battery: (a) and (b) as a function of component size and (c) and (d) as a function of the installation year. 
The taxes on self-consumed PV energy, which correspond to the so-called EEG Umlage, have not been taken into account in this study, as the project of reference was inaugurated before their application was set in Germany, in 2014. In addition, this is in line with the European Union's new Renewable Energy Directive, which has recently banned discrimination against solar energy producers, including a ban on taxing self-consuming solar systems of more than 10 kWp until at least year $2026 .{ }^{39}$

\section{E. Model convergence: Influence of the time-step resolution}

The potential inaccuracies arising from the low data resolution in building energy simulations have been noticed in the scientific community. ${ }^{19}$ Recently, Cao et al. studied systematically the accuracy of PV battery residential systems, ${ }^{40}$ concluding that $1 \mathrm{~h}$ time-resolution was a too coarse resolution in the majority of residential cases, especially when no battery is in play and the generation and consumption profiles are very variable. However, Quoilin et al. showed in a recent study ${ }^{41}$ that the influence of time-resolution was negligible through its evaluation of several European household profiles.

In this study, the available high-resolution data have been used to study the role of the simulation time-step, by running the simulation on different time resolution scales, obtained through a linear interpolation of the original data, on a $1 \mathrm{~s}$ basis, to coarser time-steps up to $1 \mathrm{~h}$.
Some of the most interesting obtained results are shown in Fig. 6. These were obtained with a PV capacity of $200 \mathrm{kWp}$ and a $200 \mathrm{kWh}$ battery.

For this case-study, the time-step has been observed to have a minor influence on the yearly self-consumption and self-sufficiency ratios [Fig. 6(a)]. Similarly, data resolution has been observed to have a minor effect-lower than $2 \%$-on the levelized cost of consumed energy (LCOE) and on battery end-of-life (EOL) estimations [Fig. 6(b)]. However, the simulation shows that the maximum values from the power exported or imported from the grid are highly dependent on the time resolution [Fig. 6(c)]. Due to these observed results, the simulations shown in Sec. IV have been computed with a $30 \mathrm{~s}$ timestep.

Here, it necessarily has to be recalled that the load profile that has been used for model validation corresponds to the aggregated demand of 23 households, as described in Sec. II. As a consequence, the stochastic fluctuations of each of the household demand curves are partially evened out. Therefore, the observed importance of simulation time-step on models' accuracy is still much lower than that which would be observed for a single household.

\section{ANALYSIS OF THE SELF-CONSUMPTION MODEL}

The model described above is used to study the influence that a number of design parameters have on the performance of the PV
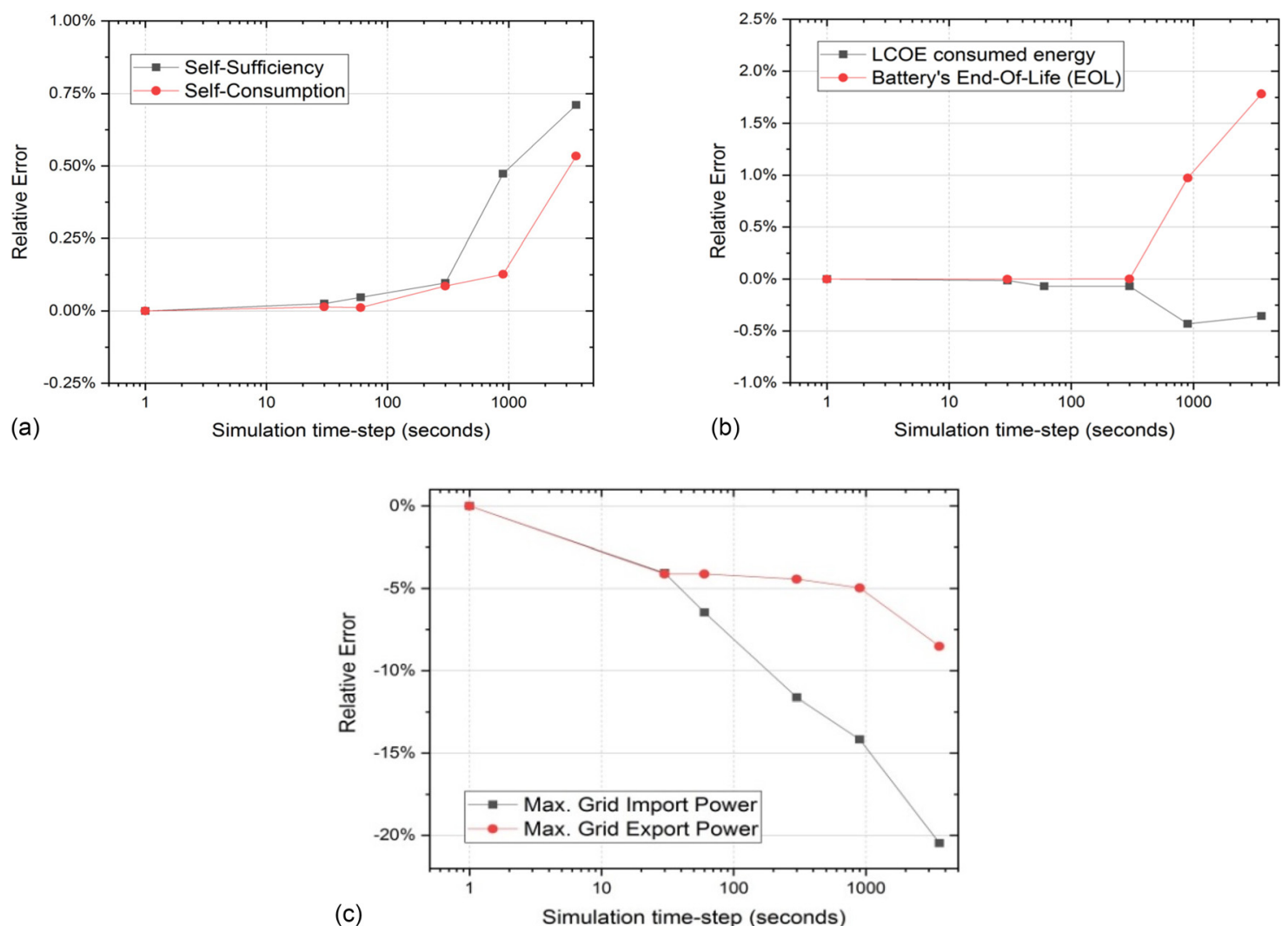

FIG. 6. Time-step convergence. Plot of the relative error from representative model variables, as compared with the results obtained with 1-s granularity. The results are shown for (a) the self-sufficiency and self-consumption indicators; (b) the LCOE and battery life predictions; (c) the maximum grid import and export power flows. 
battery system. Several indicators are of importance concerning the design of the performance of distributed energy resources (DERs), of which the most relevant are self-consumption and self-sufficiency. Even though some alternative definitions have been proposed, the consensual definition of self-consumption identifies this variable with the fraction of self-consumed PV energy related to the total energy generation, as shown in Eq. (10)

$$
\text { Self-consumption }=\frac{E_{\mathrm{PV}-\text { to-Load }}}{\mathrm{E}_{\mathrm{PV}, \text { produced }}}[\%] .
$$

Meanwhile, self-sufficiency is the ratio between the self-consumed PV energy and the global energy consumption and expresses the level of autarky from the grid

$$
\text { Self-sufficiency }=\frac{\mathrm{E}_{\mathrm{PV}-\text { to-Load }}}{\mathrm{E}_{\mathrm{Load}, \text { total }}}[\%] .
$$

These indicators, based on the yearly balance of on-site PV generation and electrical consumption, are two of the main variables analyzed in Sec. IV.

Note that a net zero energy balance with the grid is reached when those indicators are equivalent, ${ }^{26}$ and that, from a wider systems perspective, a high self-consumption is more a constraint than an aim, as the grid capabilities to embrace or "store" excess power are limited. On the other side, a higher self-sufficiency or autarky from fossil fuels is directly related to a higher integration and share of renewables.

In other publications, ${ }^{42,43}$ self-consumption and self-sufficiency are indicated or analyzed in an analogous manner through the load matching or the load cover indexes. These, as well as the so-called grid interaction index, present more detailed information about the timedependent interplay and correlation between on-site generation, consumption, and the grid. This detailed information is of vital relevance for the design of the distribution grid and main feeders, for evaluating the needs for seasonal storage, comparing different local energy sources, or evaluating the effectiveness of different grid code policies and market conditions. However, the results shown in Secs. IV and V are restricted to the yearly indicators (Eqs. 10 and 11), and the more detailed daily indicators are only shown for a representative design configuration in Appendix C.

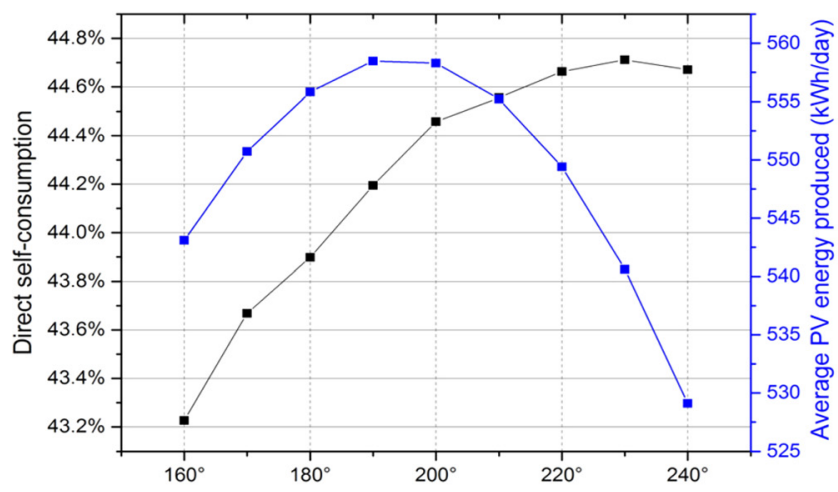

(a)

Azimuth angle
In Subsections IV A-IV C, the most relevant design parameters, including the orientation of the PV panels, the size of the PV and the battery, and the size of the power converters and inverters are investigated with respect to the economic indicators, as well as their effects on self-consumption and self-sufficiency. Besides, Subsection IVD analyzes the importance of the lifetime estimation of the PV panels and the battery and the effects that their degradation causes on the above-mentioned indicators.

\section{A. PV orientation}

As presented in Sec. III A, the PV-lib toolbox was used to simulate the effects of the module orientation on the indicators of interest. The orientation of the PV modules is usually limited by the orientation of the building, available rooftop area, and other particular boundary conditions. However, there is always a certain degree of freedom, which makes this parameter interesting to be studied in the system design phase. It is a fact that the orientation that maximizes PV generation generally differs from the one that optimizes the selfconsumption capabilities, which is mainly determined by the power consumption habits. Therefore, a trade-off between these two parameters is desired.

Figure 7 gathers the self-consumption and the PV energy production in the same graph as a function of the azimuth angle (a) and of the tilt angle (b). For the analysis of the azimuth angle presented in Fig. 7(a), a tilt angle of $30^{\circ}$ is selected as a trade-off between energy production and self-consumption. Meanwhile, an azimuth angle of $200^{\circ}$ is considered for the tilt analysis shown in Fig. 7(b). Figure 7(a) shows that the azimuth angle that maximizes self-consumption is around $210^{\circ}$, while the maximum PV power generation is obtained at an azimuth of around $195^{\circ}$. This difference is due to the higher power demand during the afternoon and evening, as visible, as shown in Fig. 3 , the consumption peaks at around $13 \mathrm{~h}$ and again around $20 \mathrm{~h}$.

In the case of surface availability restrictions, the PV modules can be placed with an east/west arrangement, thereby reducing the required space to stave off shading losses. From the simulation results, it has been observed that an increase in $25-30 \%$ in power density $\left(\mathrm{kWp} / \mathrm{m}^{2}\right)$ can be achieved with this type of arrangement. However, in

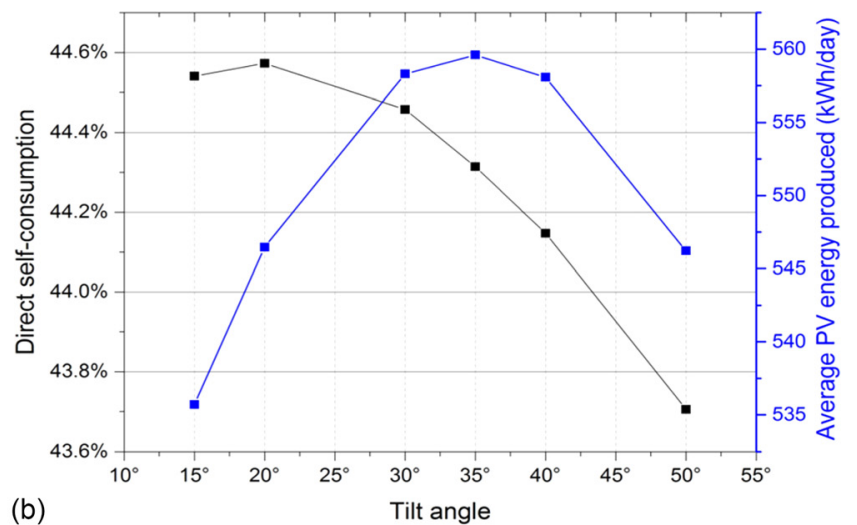

(b)

FIG. 7. Self-consumption and PV energy production as functions of (a) azimuth angle and (b) tilt angle. These results were obtained with a PV installed capacity of $200 \%$ the maximum load. 
terms of self-consumption, it leads to a $6 \%$ reduction in comparison to the south-facing arrangement.

\section{B. PV and battery size}

The analysis of the installed PV power is shown in Fig. 8. It is divided into economic aspects, self-consumption, and self-sufficiency results. First of all, LCOE is observed in Fig. 8(a) to be a convex function of PV capacity, having its minimum value at around $200 \mathrm{kWp}$ independently of the battery size. If no scale effects were taken into account, the minimum value of LCOE would move towards a smaller PV capacity, about $150 \mathrm{kWp}$.

Figures 8(b) and 8(c) represent, respectively, the evolution of selfconsumption and self-sufficiency as PV capacity is increased. A larger PV system leads to rapid increase in self-sufficiency for PV power lower than $100 \mathrm{kWp}$. The effect of larger PV power is less noticeable, slowing the self-sufficiency rise as the PV power increases. Inversely, the self-consumption rate asymptotically tends towards zero as PV capacity grows, as shown in Fig. 8(c). The effect of the adoption of a battery storage system is also shown in Figs. 8(b) and 8(c). Both selfconsumption and self-sufficiency ratios can be observed to increase in a similar rate with an increasing battery size, although a greater effect can be observed on self-sufficiency.

The implications of the battery size are analyzed in Fig. 9. Note that, with a battery capacity of $150 \mathrm{kWh}$, the increasing rate of selfsufficiency and self-consumption slowdown. This amount of storage capacity, $150 \mathrm{kWh}$, corresponds approximately to the energy that is consumed during the night time (between 18 and $9 \mathrm{~h}$ ). For this particular case study, it represents $55 \%$ of the total energy demand. Having a look at the financial aspects of the consumed energy in Fig. 9(a), LCOE is observed to increase with bigger battery size, showing that the adoption of a battery does still not add economic value with current market prices. Nonetheless, the LCOE can be maintained at a lower value than $30 \mathrm{ct} € / \mathrm{kWh}$, which is the price of the electricity consumed from the grid. For example, if the peak PV power is $200 \mathrm{~kW}$, up to approximately $250 \mathrm{kWh}$ of battery can be added leading to an LCOE increase from $25 \mathrm{ct} € / \mathrm{kWh}$ to $30 \mathrm{ct} € / \mathrm{kWh}$. This battery would lead to a final LCOE similar than that of the grid, while increasing the self-sufficiency rate from $38 \%$ to over $72 \%$, and the self-consumption from $20 \%$ to $38 \%$.

Additionally, the reader must note that the LCOE of the consumed energy shows a slight S-shape. This can be explained, on the one hand, by the effect of the scale in a battery price described in Sec. III D. On the other hand, the amount of energy consumed during night time determines the battery capacity at which this S-shape is noticeable.

Figure 9(b) shows the LCOE of the stored energy as a function of the battery capacity and PV power. This graph confirms the conclusions explained in the previous paragraph. The installation of a battery is not profitable unless the LCOE of the stored energy is lower than the price paid for the grid energy (in this case, $30 \mathrm{ct} € / \mathrm{kWh}$ ), which is not the case for the current market prices. The minimum LCOE of the stored energy is reached for a battery capacity of around $150 \mathrm{kWh}$, which is the region of the S-shape in Fig. 9(a).
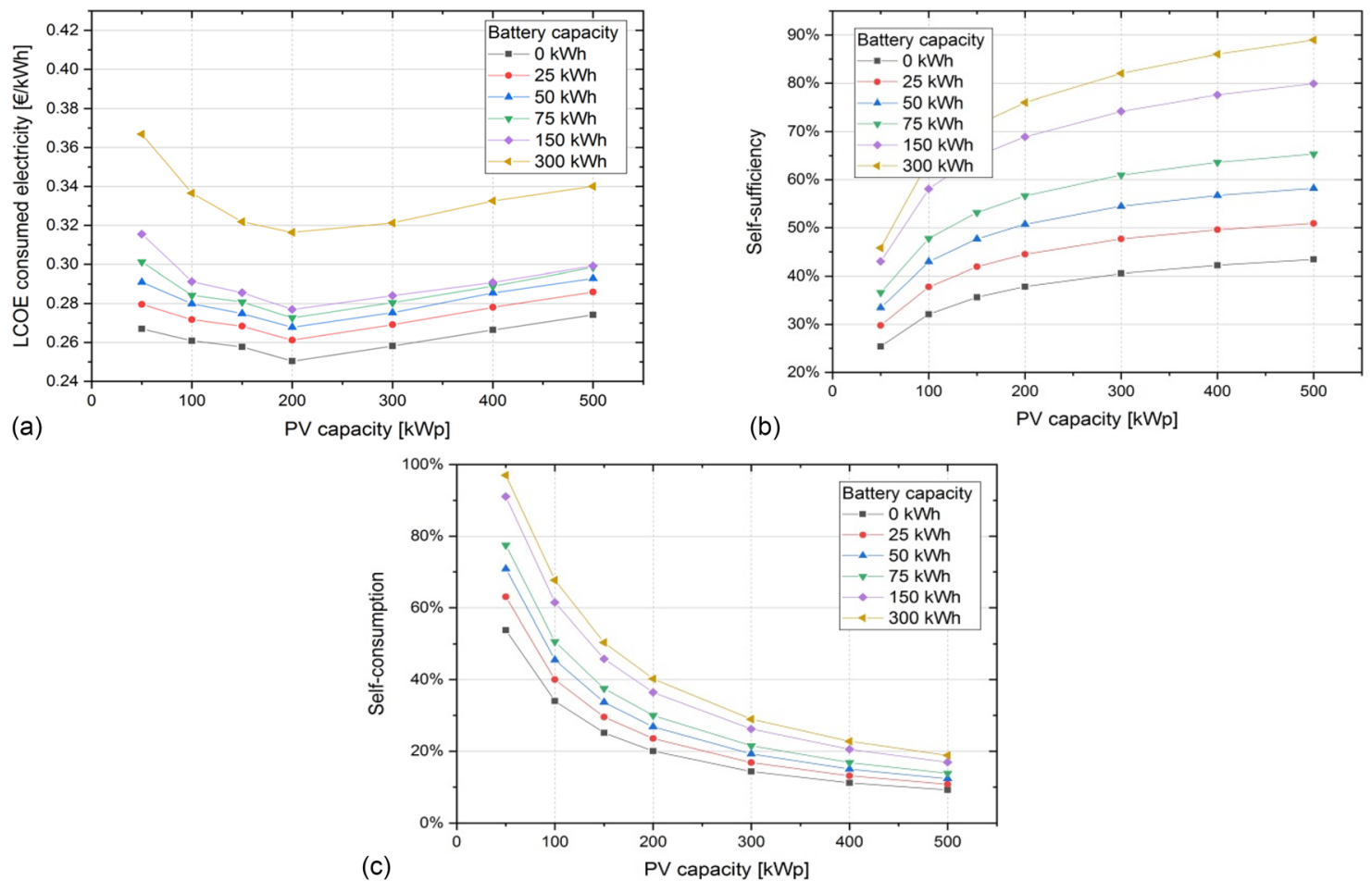

FIG. 8. Effects of PV installed capacity, in kWp, (a) on the levelized cost of consumed energy, (b) on the self-sufficiency, and (c) on the self-consumption indexes. 


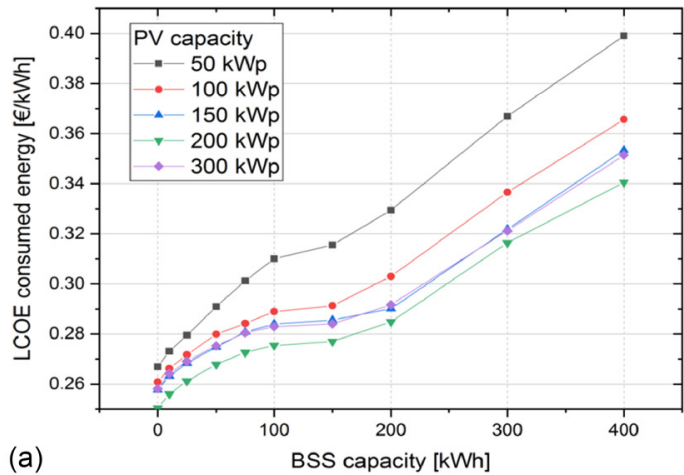

(a)

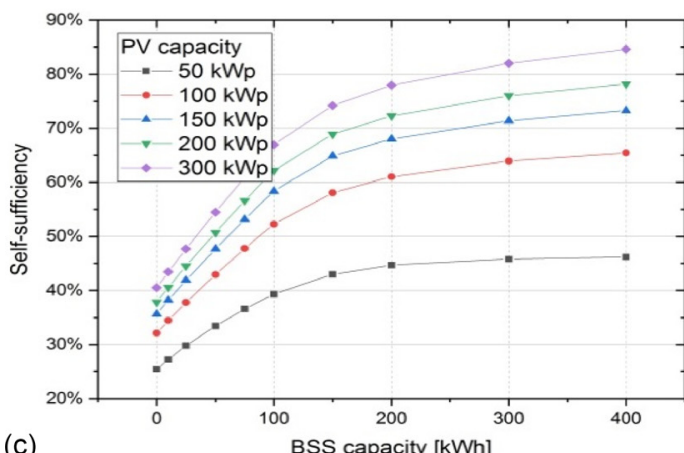

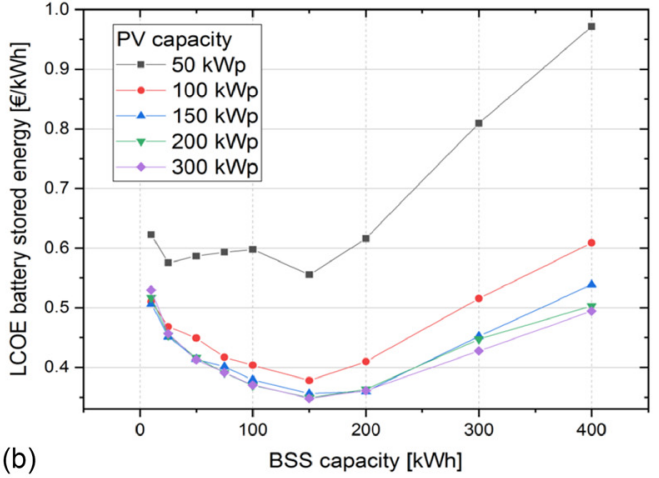

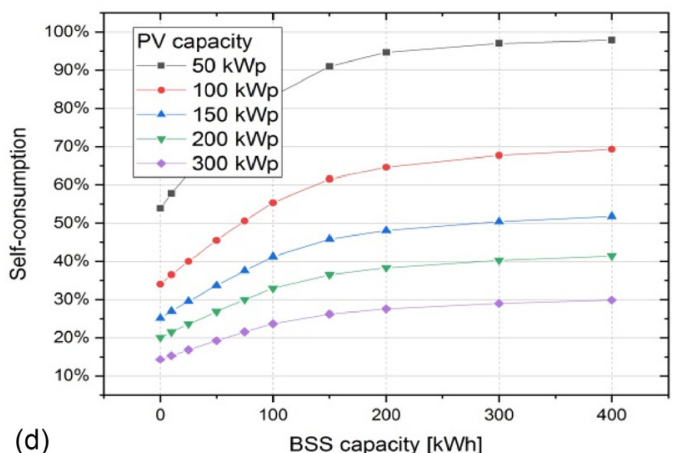

FIG. 9. Effects of battery installed capacity, in kWh, on the levelized cost of consumed and stored energy and on the self-sufficiency and self-consumption indexes.

Figures 9(c) and 9(d) show the evolution of self-sufficiency and self-consumption rates as function of battery capacity and PV power. They are equivalent to Figs. 8(b) and 8(c) but representing the battery capacity in the horizontal axis and the PV power as different lines. The growing of both indexes is clearly appreciated in these two graphs, as well as their slower increase as battery capacity grows. Inversely to the effects of growing PV capacity, the adoption of a battery has greater consequences on self-sufficiency than on the self-consumption indicator.

\section{Size of power converters}

The analysis of the effect that the size of the PV inverter and the battery bidirectional converter has on the LCOE is summarized in Fig. 10. On the one hand, the ratio between the PV inverter and the PV array peak power is analyzed in Fig. 10(a), which has the LCOE of the consumed energy in the vertical axis. It can be seen that the optimal ratio is around $75 \%$ for the analyzed application, independently of the PV capacity. Especially remarkable is that solar inverter clipping occurs by increasing the operating modules voltage, which hence decreases efficiency from the modules to an operation point with a lower power than the MPP. Therefore, no higher degradation is expected in the inverter due to power clipping.

On the other hand, Fig. 10(b) analyzes the ratio between the battery capacity $(\mathrm{kWh})$ and the battery converter power $(\mathrm{kW})$, which is usually expressed in units of hours. The parameter represented in the vertical axis is the LCOE of the stored energy. As it can be observed, the most economical ratio, independent of battery and PV capacities, is found between $5 \mathrm{~h}$ and $9 \mathrm{~h}$. The meaning of this finding is that a battery system sized to cover overnight energy demand is the best option. Further increase in self-consumption or self-sufficiency would require of day-to-day energy storage, which considerably increases the total cost. This cost increase is due to the seldom use of this additional capacity, which is only needed during consecutive days with low irradiation. This finding applies only for batteries installed with selfsufficiency and self-consumption purposes, exclusively, and may vary considerably if additional ancillary services are considered. In the latter case, the higher cost of higher power converters may be overcome by the additional revenue that these services can generate.

\section{PV and battery degradation}

As described by Eq. (4), the derating rate $e$ already accounts for the degradation of the PV field and battery within the LCOE calculations presented above. In this study, the derating rate has been assumed to be $0.7 \%$ /year, which translated into a capacity fade of about $20 \%$ within a 30 year period, matching most of today's PV module specifications and warranties. Besides, battery aging has also been taken into account within all previously shown simulations to the predict battery component replacement needs, by estimating the end-oflife (EOL) through a linear extrapolation of the average capacity fade slope obtained within the last 2 months of the first year performance. By doing that, the quasi-exponential calendric aging phase, often characterized by the Arrhenius equation due to its temperature 

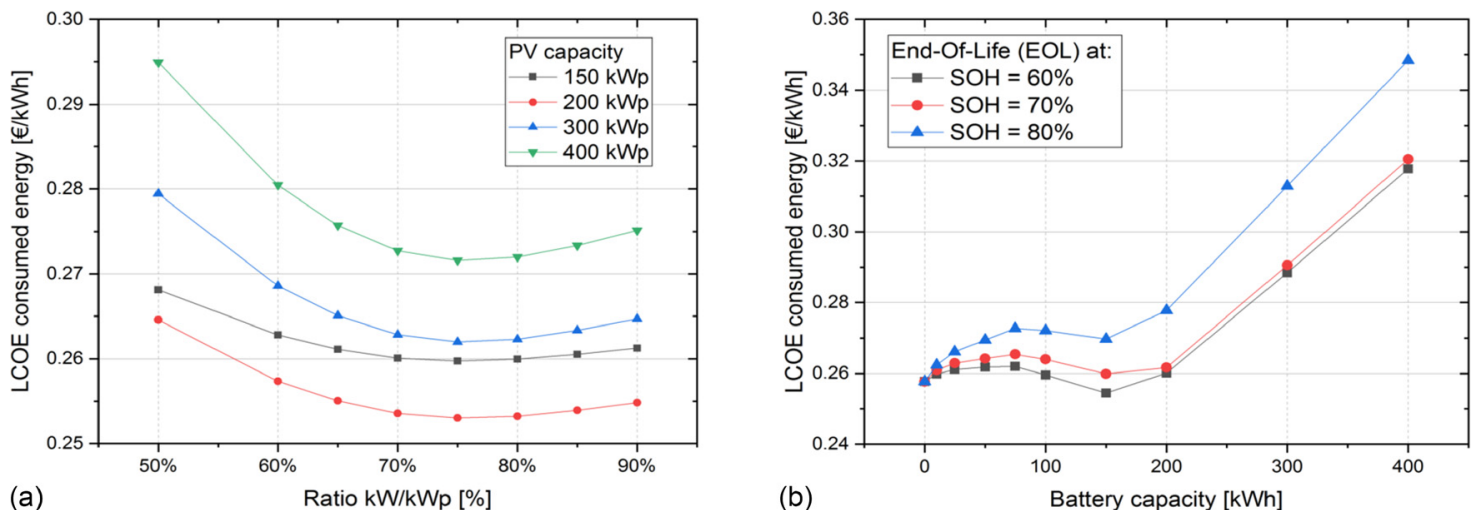

FIG. 10. Effect of the rated power of the power converter on the LCOE: (a) ratio between PV inverter rated power and PV field peak power and (b) ratio between battery capacity and battery bidirectional converter rated power.

dependency, is considered to no longer be significantly non-linear after the first year of operation and until its EOL.

Within the simulation, the EOL point is reached at an arbitrarily defined state of health (SOH) limit, at which the battery degradation enters again a non-linear aging phase where capacity rapidly drops and forces the unit replacement. Although scientific understanding of aging mechanisms of lithium-ion batteries keeps improving and a growth of the solid electrolyte interphase (SEI) at the anode electrode is often identified as the main factor for battery's EOL, many difficulties remain to identify and understand the physical triggering factors that cause this accelerated aging stage. Different cyclic aging studies have found this to be triggered at about an $\mathrm{SOH}$ between 70 and $80 \%$. Hence, in all previously shown results, the SOH limit was set to $75 \%$. Nonetheless, this may be strongly dependent on battery's chemistry and design. Therefore, as this parameter is identified as a very significant factor for the economic evaluation of the battery component, Fig. 11 shows the obtained LCOE of the consumed and stored energy for different battery sizes and three different EOL criteria, considering that the battery can be used until SOH declines to $80 \%, 70 \%$, or $60 \%$.

As commented in Sec. IV B, the installation of a battery is not profitable with the current market prices, regardless of the EOL criteria, given that the LCOE of the stored energy is higher than the electricity cost from the grid (30 ct€/kWh), as shown in Fig. 12(a). However, a battery that can be used down to $60 \% \mathrm{SOH}$ achieves, with respect to a battery that reaches EOL at $80 \% \mathrm{SOH}$, a $15 \%$ decrease in the LCOE of the stored energy [Fig. 12(a)] and also a significant reduction in the LCOE of the consumed energy [Fig. 12(b)], e.g., of up to $8.8 \%$ for a battery size of $400 \mathrm{kWh}$.

On the other hand, PV and battery performance variations as the system age affect, trivially, the self-consumption and self-sufficiency rates, too. However, the self-sufficiency and self-consumption rates that have been shown in previous figures are, as in most existing software, the values that had been obtained through the analysis of the first year of operation only. Figure 12 shows the influence that PV and battery degradation is observed to have onto these indicators, where the results are expressed as a function of the battery installed capacity for a PV system of $200 \mathrm{kWp}$. The project horizon is, as mentioned in Sec. III C, set to 25 years.

Comprehensively, the degradation of the PV system increases the self-consumption rate, as a bigger portion of the total solar harvested energy can be directly consumed [Fig. 12(b)]. In contrast, the selfsufficiency rate is negatively affected by PV degradation, as the total energy consumed from the grid increases [Fig. 12(a)]. Battery degradation is observed to affect negatively both self-consumption and self-

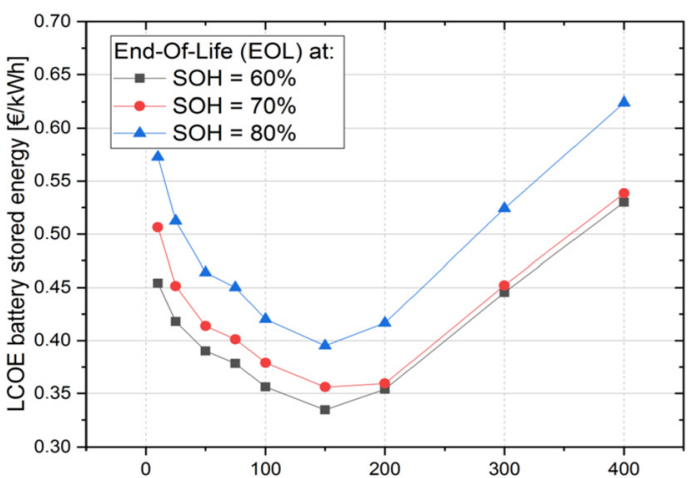

(a)

Battery capacity $[\mathrm{kWh}]$

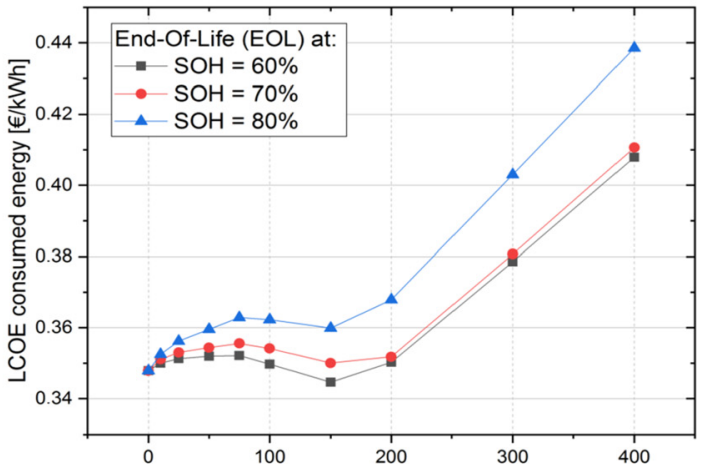

(b)

Battery capacity $[\mathrm{kWh}]$

FIG. 11. Effects of battery end-of-life (EOL) criteria on (a) LCOE of the stored energy and (b) LCOE of the consumed energy. These results are obtained for a PV capacity of $150 \mathrm{kWp}$. 

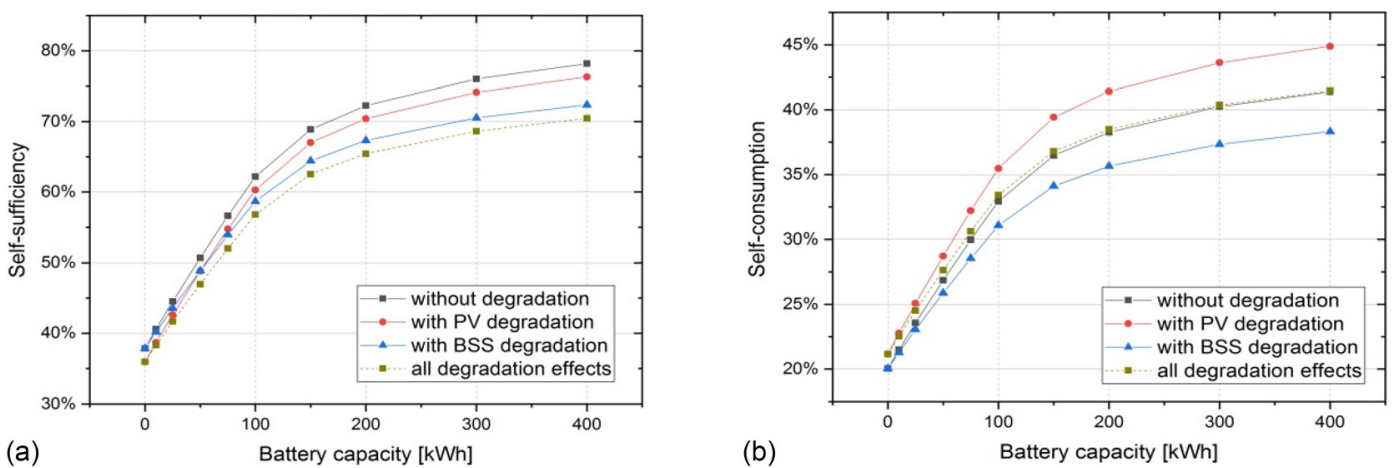

FIG. 12. Effect of PV and battery capacity degradation on (a) self-consumption rate and (b) self-sufficiency rate. Shown results have been obtained with a PV capacity of $150 \mathrm{kWp}$.

sufficiency rates, especially self-sufficiency estimates. Adding up both effects, it can be concluded that no large divergence is to be expected within the self-consumption rate when ignoring the PV and battery aging effects, as these two have opposite effects on this indicator. However, self-sufficiency is considerably affected by capacity degradation of both components, and an error of up to $8 \%$ is obtained, e.g., for the system with $200 \mathrm{kWp} \mathrm{PV}$ and a $400 \mathrm{kWh}$ battery. Besides, it can be concluded that PV degradation has a larger impact on the selfconsumption rate, whereas battery degradation penalizes more the self-sufficiency estimate.

\section{RETROFITTING MARKET POTENTIAL}

Due to the established feed-in tariff (FIT) policy, the amount of installed PV capacity grew rapidly in Germany, especially after 2004, booming between 2009 and 2013. ${ }^{44}$ This subsidy is paid for 20 years, even though the panels have a longer lifetime. For this reason, Fig. 13(a) shows the amount of installed PV capacity which will run out of the FIT policy within the near future. The termination of the FIT may be a triggering factor for the installation of batteries, aiming the owners at an increased self-consumption level and in order not to freely give away excess PV power to the grid. This has commonly received the name of retrofitting and is probably one of the biggest potential markets for the adoption of residential or commercial battery storage systems.

The reason is simple: an investment in a battery system for an increased self-consumption is not profitable in a scenario where the FIT is high, as the economic benefits achieved by the energy storage system (ESS) come from the difference between the grid tariff and the feed-in tariff. Hence, this margin needs to be higher than the storage LCOE for the investment to be profitable. As shown in Sec. IV, this is not the current scenario. However, if no FIT is paid to excess PV power, the profitability of an ESS can be reached sooner, as the battery can reach profitability as soon as the LCOE for stored energy reaches lower values than the grid tariff.

With regard to this market potential for increased selfsufficiency, Fig. 13(b) gathers the obtained simulation results reflecting the variation of the LCOE of consumed energy achieved by the adoption of an ESS as a retrofit option for existing PV installations that have ended their FIT period. Within these simulations, the prices for the system components have been estimated based on the priceexperience curves described in Sec. III D, which predict decreasing component prices due to economies of scale effects, and the electricity tariff is taken as of today's level. Several simulations have been performed with different sizes of the battery up to $300 \mathrm{kWh}$, as shown in
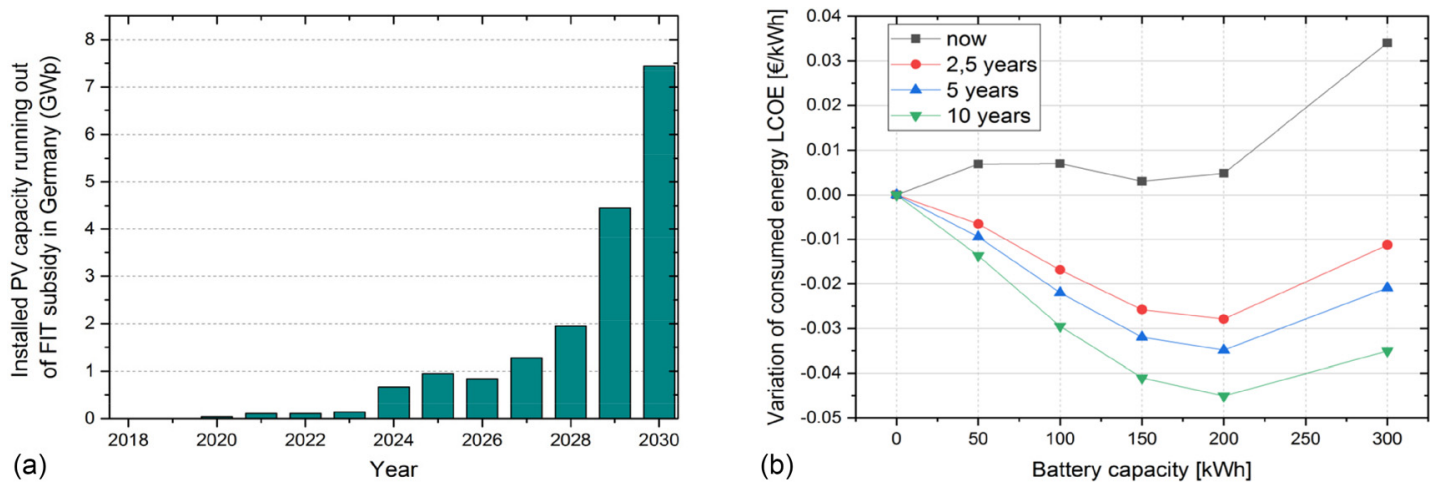

FIG. 13. Upcoming scenario for battery retrofitting of the existing PV system: (a) Prognosis of PV installed capacity, in Germany, which will finish receiving the FIT subsidy. (b) Variation of PV battery LCOE as a function of the installed battery capacity in PV installations for which the FIT subsidy has prescribed. 
the horizontal axis. Moreover, the four lines displayed in the figure represent the results for the current market conditions (black) and those expected in 2.5 years (red), 5 years (blue), and 10 years (magenta). A variation of the LCOE for the consumed energy greater than 0 means that the investment in the battery is not profitable, given that the cost of energy after the installation of the battery is higher than before. Meanwhile, a negative variation on LCOE means that cheaper energy costs are achieved by the adoption of the battery in the plant. Note that the profitability of adopting a lithium-ion battery is predicted to increase during the upcoming years, mainly due to the expected price reduction of this kind of battery. Moreover, there is an optimal battery size in all the studied scenarios, which is around $200 \mathrm{kWh}$ for the considered case study. Finally, these results indicate that the adoption of battery storage for the retrofitting market, with the aim of increasing self-consumption and self-sufficiency, can achieve cost effectiveness within the next few years and, for the studied case, even in less than 2.5 years.

From data published by the Federal Network Agency (Germany), a monthly rate of 160-190 MWp of new PV capacity was registered in Germany during the last year (2017). However, only 7.5 MWh of batteries were installed per month. Hence, the amount of batteries that are deployed represents only a fraction of $4-4.8 \%$ with respect to newly installed PV capacity. These values show, however, and taking into account the non-profitability of ESS to date, that a relevant fraction of the population is already willing to pay more to increase self-consumption and selfsufficiency of their PV installations.

The results obtained in this study point to profitable PV battery systems in the near future. The retrofitting market can be estimated to achieve a volume of more than $100 \mathrm{MWh} /$ year by 2021 and up to $1 \mathrm{GWh} /$ year by 2025 . Besides, if feed-in tariffs keep decreasing and electricity consumer tariffs increase, economic profitability of battery adoption could also be similarly reached in the near future, thus opening the door to an even bigger market for residential PV coupled batteries. Additionally, this analysis and the predictions of economic profitability of PV battery systems can be extended to other countries markets where FIT subsidies are not available anymore, such as Italy or Spain. Last but not least, the recent support shown by the European Union with the New Renewable Energy Directive on self-consumption and self-sufficiency models can force the application of more favorable regulatory frameworks in all member states, e.g., banning the sun tax or allowing for peer-to-peer transaction possibilities within the shortterm, which could allow for the diffusion of similar energy models as the presented herein.

\section{CONCLUSIONS}

In this paper, a decentralized and highly self-sufficient energy model is presented and proposed for residential or commercial applications through the description of a reference district project, the main power sources of which are PV and a cogeneration unit. Following, the most relevant technical and economic aspects of such an energy model are evaluated and studied from numerical simulations, using a model that is developed and validated with real measurement data.

A number of variations on the real, measured case study have been simulated, and the obtained results have been analyzed in order to provide a good understanding of the current situation, and the most remarkable variables to be taken into account during the design phase of similar power supply systems. The extracted conclusions from this use case are applicable to other residential or commercial PV systems with a similar penetration of PV capacity and similar power consumption distribution.

The optimal orientation of the PV panels for a highly selfsufficient model has been proven to depend not only on solar resources but also on load profile distribution. For example, in the case studied in this paper, maximum PV self-consumption is achieved at an azimuth of $230^{\circ}$, whereas the highest PV generation is achieved with an azimuth of $190^{\circ}$. Also related to technical characteristics of the power system is the size of the installed power converters. On the one hand, the most informative ratios have been found to be the ratio between the inverter rated power and the PV peak power and the ratio between the battery capacity and the rated power of the bidirectional battery converter. The optimal values of both ratios have been proved to be independent of PV and the battery size and dependent only on irradiance and demand characteristics. For the case study analyzed in this paper, the optimal PV inverter power should be $75 \%$ of the PV peak power, while the power of the battery converter $(\mathrm{kW})$ should be between $11 \%$ and $20 \%$ of battery capacity ( $\mathrm{kWh}$ ) or, what is equivalent, between $5 \mathrm{~h}$ and $9 \mathrm{~h}$.

Besides, the influence that the PV panels' and batteries' degradation has on the self-consumption and self-sufficiency of the system has also been studied. While PV capacity fade increases the rate of selfconsumption, both degradation phenomena imply a reduction of the self-sufficiency rate. Hence, PV and battery aging are found to be essential factors to obtain accurate estimation rates of self-sufficiency on the mid-term. Regarding the battery aging, it has been concluded that the end-of-life criterion is a parameter that deserves proper attention. The uncertainty related to the EOL of the battery has been quantified as around $15 \%$ of the stored energy LCOE, by investigating EOL between $60 \%$ and $80 \%$ state-of-health $(\mathrm{SOH})$, thus pointing out the high sensitivity of the profitability of the system with respect to this characteristic.

The analysis of the current market scenario shows that even though the installation of battery systems favors the integration of higher shares of renewables, it is not yet profitable for the end-user. Therefore, current scenarios of PV battery self-consumption systems are explained by the endogenous benefits of self-sufficiency models and the good acceptance that this model has among German society. Nonetheless, from the evaluation of the retrofitting market, gathered in Sec. V, which has been identified as a great market potential for the deployment of ESS within existing PV systems, it is predicted that once FIT are no longer available, cost effectiveness of PV battery could be reached within the next 2.5 years. The major hints and conclusions of this analysis apply, with minor nuances, to other markets corresponding to countries where FIT subsidies are not available and have similar electricity prices.

\section{APPENDIX A: EXPERIMENTAL RESULTS-LOOK-UP TABLES FOR THE BATTERY MODEL}

The experimental results for the open-circuit voltage and the entropic coefficient measurements for the reference battery cell are shown in Fig. 14. The open-circuit voltage (OCV) curve was 

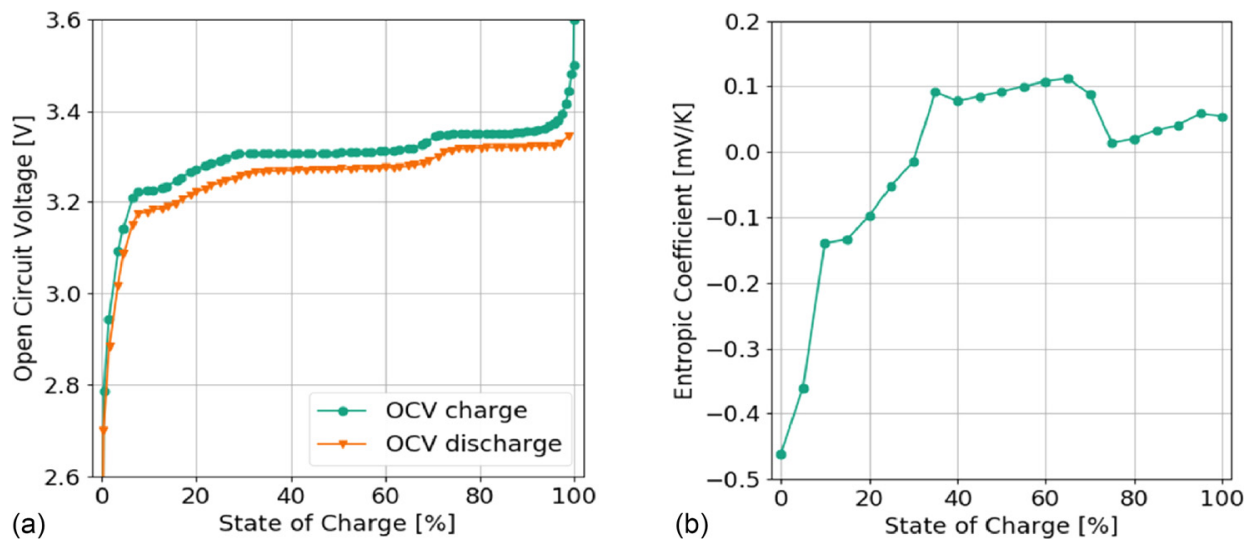

FIG. 14. Experimental results for the open-circuit and entropic coefficient results, as a function of the state-ofcharge, obtained for the LFP lithium-ion reference battery cell.
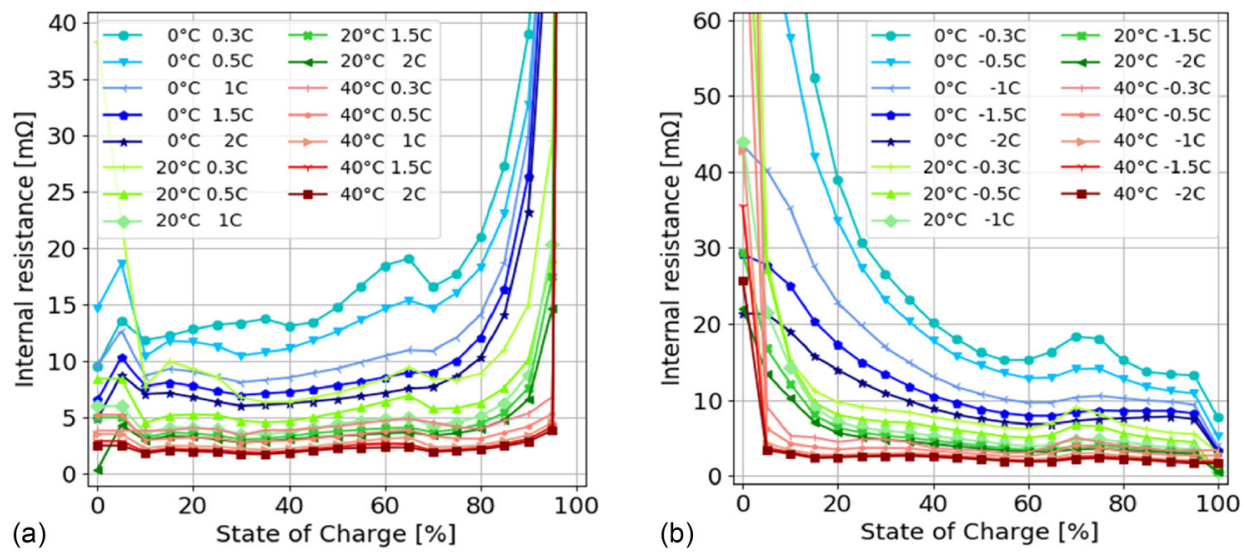

FIG. 15. Experimental results for the internal resistance, as a function of the stateof-charge, the temperature, and the current rate, obtained for the LFP lithium-ion reference battery cell.

measured at different states of charge (SOC) and at different temperatures, choosing a relaxation time of $6 \mathrm{~h}$ for the voltage to settle. Since a LFP cell is analyzed, the hysteresis of the OCV is also taken into account. The entropic coefficient was measured through potentiometric tests ${ }^{45}$ and verified by isothermal calorimetry. ${ }^{46}$
In order to generate the internal impedance, charge and discharge current pulses where performed at different SOC, current rates-from $\mathrm{C} / 3$ to $2 \mathrm{C}$-, and ambient temperatures from $0{ }^{\circ} \mathrm{C}$ to $40^{\circ} \mathrm{C}$. The current pulses that are applied for a length of $30 \mathrm{~s}$ and the results of the parametrization are shown in Fig. 15.

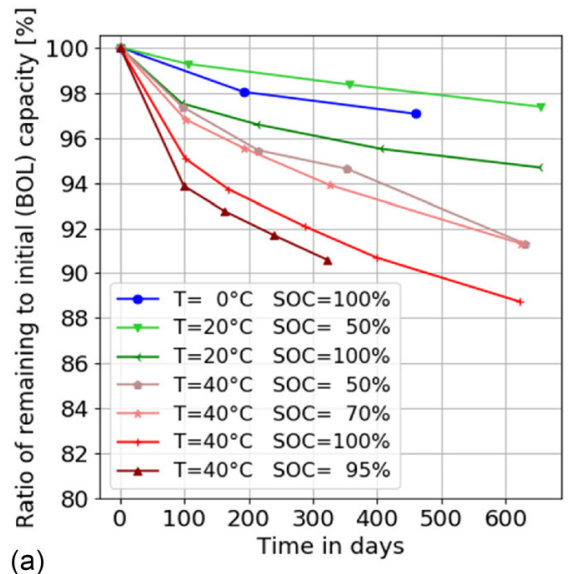

(a)

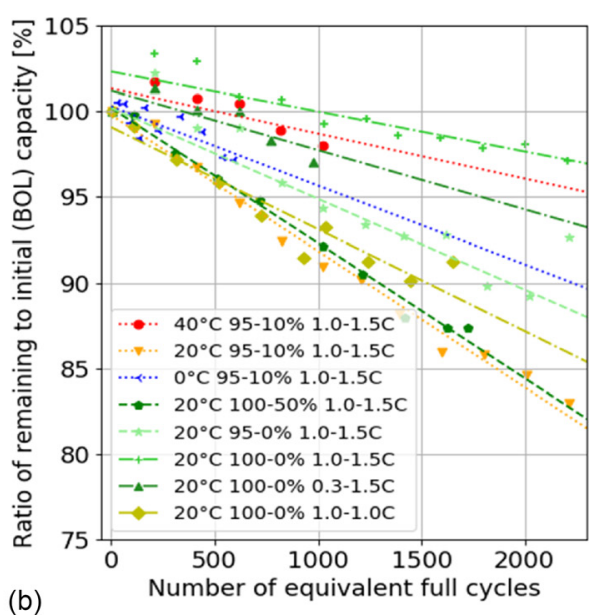

FIG. 16. Experimental results for the degradation tests including calendric and cycle aging for the LFP lithium-ion reference battery cell. 


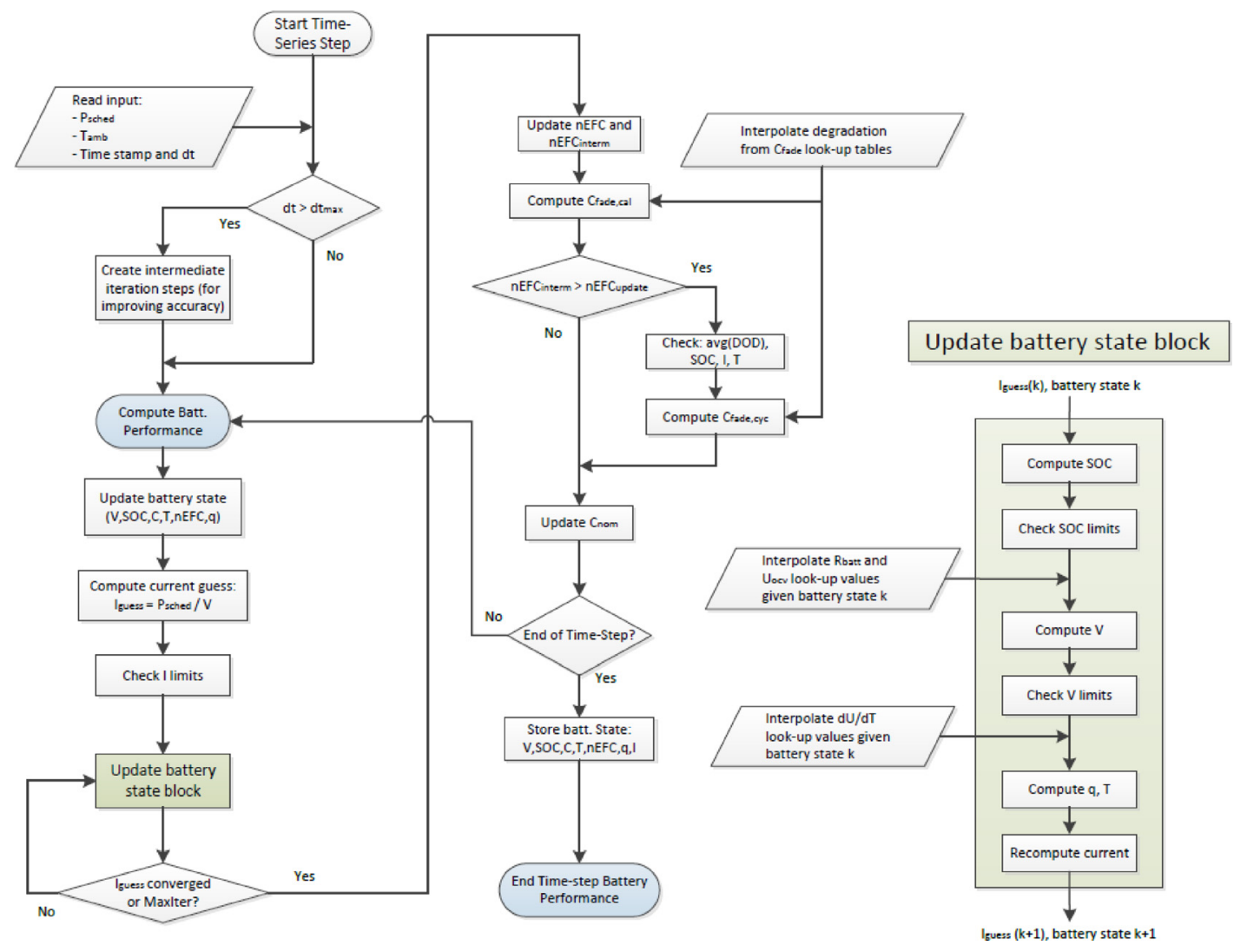

FIG. 17. Flowchart of the implemented battery model.

The characterization of the battery degradation was divided into calendric and cycle aging tests. Capacity fade due to calendric aging, under different storage SOC and temperature conditions, was analyzed for a period of almost two years. Cycle aging tests included constant current charge and discharge cycles at different current rates, depth-of-discharge, and surrounding ambient temperatures. The results are gathered in Fig. 16.

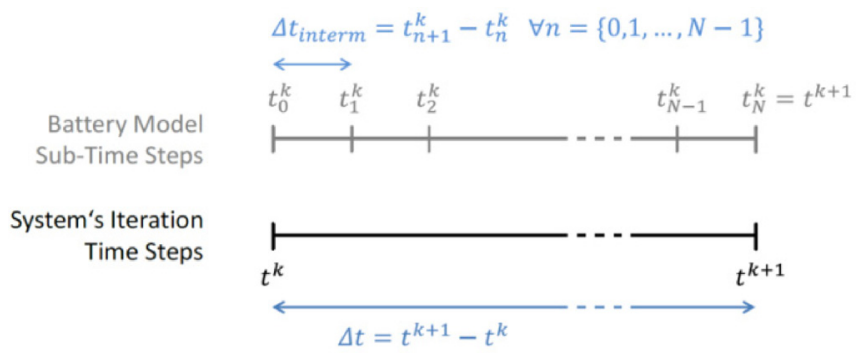

FIG. 18. Iterative scheme employed for the time-integration of battery model performance.

\section{APPENDIX B: FLOWCHART OF THE BATTERY MODEL}

The flowchart shown in Fig. 17 details the procedural execution of the battery model throughout the time-series simulation. As it can be observed, the capacity of the battery keeps decreasing as time advances and as the number of equivalent full cycles (EFC) increases, depending on the empirically based coefficients for calendric and cycle aging, respectively.

Note that for simulations running over datasets with large time-steps (greater than $5 \mathrm{~min}$ ), the battery model employed in this paper uses an intermediate time discretization which increases the accuracy of the estimations regarding battery performance and degradation (Fig. 18).

\section{APPENDIX C: LOAD MATCH AND GRID INTERACTION RESULTS}

Figure 19 contains results corresponding to the daily Load Match (LM) and Grid Interaction Index (GI) indexes. These correspond to the results from the simulation with a PV capacity of 200 kWp and a battery of $200 \mathrm{kWh}$. Note that, in Fig. 19(a), the average 
Daily load match and grid interaction indexes

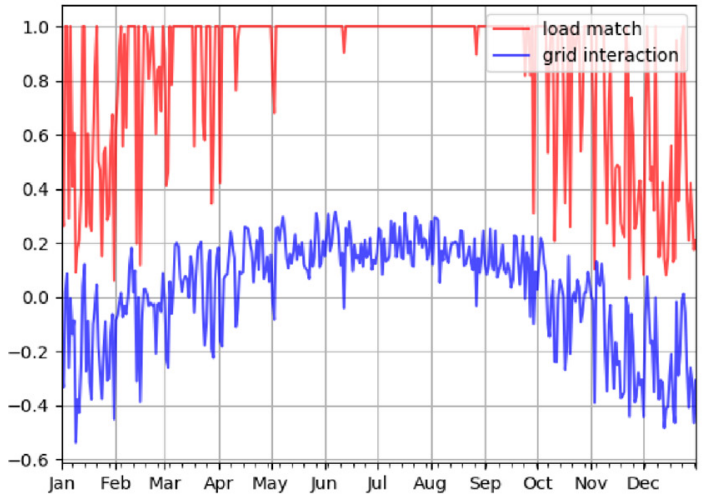

(a)

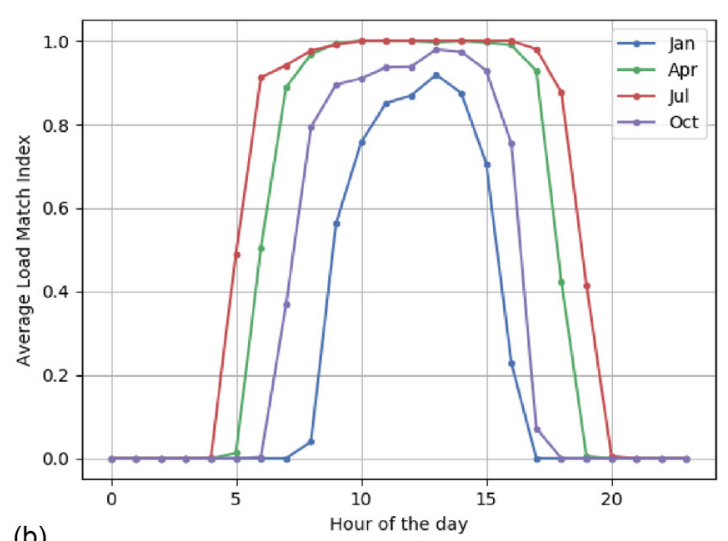

(b)

FIG. 19. Left figure (a) shows obtained daily load match and grid interaction indexes throughout one year. On the right (b), average hourly load match indexes are plotted for 4 representative months. The results shown have been obtained with a $200 \mathrm{kWp} \mathrm{PV,} 200 \mathrm{kWh}$ battery system.

grid interaction is approximately zero, which implies an almost net zero-energy balance throughout the year.

\section{REFERENCES}

${ }^{1}$ C. Kost, S. Shammugam, V. Jülch, H.-T. Nguyen, and T. Schlegl, Levelized Cost of Electricity-Renewable Energy Technologies (Fraunhofer Institute for Solar Energy Systems ISE, Freiburg, 2018).

${ }^{2}$ I. Pineda and P. Tardieu, http://WindEurope.org for Wind in Power 2017: Annual Combined Onshore and Offshore Wind Energy Statistics, 2018.

${ }^{3}$ Agora Energiewende, 12 Insights on Germany's Energiewende-a discussion paper exploring key challenges for the power sector (Agora Energiewende, 2013).

${ }^{4} \mathrm{M}$. Zebarjadi and A. Askarzadeh, "Optimization of a reliable grid-connected PV-based power plant with/without energy storage system by a heuristic approach," Sol. Energy 125, 12-21 (2016).

${ }^{5}$ A.-L. Klingler, "Self-consumption with PV + Battery systems," Appl. Energy 205, 1560-1570 (2017).

${ }^{6}$ European Parliament and Council, Official Journal L156 of the European Union, 2018.

${ }^{7}$ A. Berrueta, M. Heck, M. Jantsch, A. Ursúa, and P. Sanchis, "Combined dynamic programming and region-elimination technique algorithm for optimal sizing and management of lithium-ion batteries for photovoltaic plants," Appl. Energy 228, 1-11 (2018).

${ }^{8}$ G. Fitzgerald, J. Mandel, J. Morris, and H. Touati, The Economics of Battery Energy Storage (Rocky Mountain Institute, 2015).

${ }^{9} \mathrm{H}$. Wirth, Recent Facts about Photovoltaics in Germany (Fraunhofer Institute for Solar Energy Systems ISE, 2018).

${ }^{10} \mathrm{Y}$. Karneyeva and R. Wüstenhagen, "Solar feed-in tariffs in a post-grid parity world," Energy Policy 106, 445-456 (2017).

${ }^{17}$ G. Masson, J. I. Briano, and M. J. Baez, "Review and analysis of PV selfconsumption policies," Report No. IEA-PVPS T1-28, International Energy Agency, IEA-PVPS, 2016, pp. 1-82.

${ }^{12}$ D. Setton and I. Matuschke, https://www.iass-potsdam.de/de/news/sozialesnachhaltigkeitsbarometer-zur-energiewende-zeigt-breite-zustimmung-aber-

zweifel-der for Soziales Nachhaltigkeitsbarometer zur Energiewende zeigt breite Zustimmung, aber Zweifel an der Umsetzung.

${ }^{13}$ European Commission, Best practices on renewable energy self-consumption, SWD(2015) 141 final, 2015.

${ }^{14}$ Bundesministerium der Justiz und für Verbraucherschutz, https://www.gesetzeim-internet.de/eeg_2014/ for $\$ 3$ Nr.19; $\$ 61$ b,k; and $\$ 95$ Nr.2 from EEG 2017, November 2018.

${ }^{15}$ Bundesministerium der Justiz und für Verbraucherschutz, https://www.gesetzeim-internet.de/stromnzv/BJNR224300005.html for Verordnung über den
Zugang zu Elektrizitätsversorgungsnetzen (Stromnetzzugangsverordnung StromNZV), November 2018.

${ }^{16} \mathrm{M}$. Koepp, L. Krampe, M. Wünsch, and H. Schalle, Mieterstrom: Rechtliche Einordnung, Organisationsformen, Potenziale und Wirtschaftlichkeit von Mieterstrommodellen (MSM) (Boos Hummel \& Wegerich (BH\&W) and Prognos AG, Berlin, 2017).

${ }^{17}$ pv magazine, https://www.pv-magazine.de/2017/03/09/pv-magazine-roundtable-geschftsmodelle-fr-gewerbespeicher/ for pv magazine Roundtable: Geschäftsmodelle für Gewerbespeicher (2018).

${ }^{18}$ A.-L. Klingler and F. Schuhmacher, "Residential photovoltaic self-consumption,” Energy Effic. 21, 121 (2018).

${ }^{19}$ R. Luthander, J. Widén, D. Nilsson, and J. Palm, "Photovoltaic selfconsumption in buildings," Appl. Energy 142, 80-94 (2015).

${ }^{20}$ J. Hoppmann, J. Volland, T. S. Schmidt, and V. H. Hoffmann, "The economic viability of battery storage for residential solar photovoltaic systems-A review and a simulation model," Renewable Sustainable Energy Rev. 39, 1101-1118 (2014).

${ }^{21}$ M. Naumann, R. C. Karl, C. N. Truong, A. Jossen, and H. C. Hesse, "Lithiumion battery cost analysis in PV-household application," Energy Procedia 73, 37-47 (2015).

${ }^{22}$ G. Merei, J. Moshövel, D. Magnor, and D. U. Sauer, "Optimization of selfconsumption and techno-economic analysis of PV-battery systems in commercial applications," Appl. Energy 168, 171-178 (2016).

${ }^{23}$ A. Braeutigam, T. Rothacher, H. Staubitz, and R. Trost, "Fact sheet," in The energy storage market in Germany (Germany Trade and Invest, GTAI, 2019).

${ }^{24} \mathrm{E}$. Barbour and M. C. González, "Projecting battery adoption in the prosumer era," Appl. Energy 215, 356-370 (2018).

${ }^{25}$ A. Pena-Bello, M. Burer, M. K. Patel, and D. Parra, "Optimizing PV and grid charging in combined applications to improve the profitability of residential batteries," J. Energy Storage 13, 58-72 (2017).

${ }^{26}$ R. Baetens, R. de Coninck, J. van Roy, B. Verbruggen, J. Driesen, L. Helsen, and D. Saelens, "Assessing electrical bottlenecks at feeder level for residential net zero-energy buildings by integrated system simulation,” Appl. Energy 96, $74-83$ (2012).

${ }^{27}$ A. Zeh, M. Rau, and R. Witzmann, "Comparison of decentralised and centralised grid-compatible battery storage systems in distribution grids with high PV penetration,” Prog. Photovoltaics: Res. Appl. 24, 496-506 (2016).

${ }^{28}$ K. Uddin, R. Gough, J. Radcliffe, J. Marco, and P. Jennings, “Techno-economic analysis of the viability of residential photovoltaic systems using lithium-ion batteries for energy storage in the United Kingdom," Appl. Energy 206, 12-21 (2017).

${ }^{29}$ J. S. Stein and B. Farnung, "PV performance modeling methods and practices," in Results from the 4th PV Performance Modeling Collaborative Workshop, IEA PVPS Task 13 (2017), pp. 1-98.

${ }^{30}$ Sandia National Laboratories, https://pvpmc.sandia.gov/applications/pv_libtoolbox/ for PV Performance Modeling Collaborative|PV-Lib Toolbox, October 2018. 
${ }^{31}$ A. Driesse, P. Jain, and S. Harrison, "Beyond the Curves: Modeling the Electrical Efficiency of Photovoltaic Inverters," in Proceedings of the 33rd IEEE Photovoltaic Specialists Conference (2008).

${ }^{32}$ D. Bernardi, E. Pawlikowski, and J. Newman, "A general energy balance for battery systems,” J. Electrochem. Soc. 132, 5-12 (1985).

${ }^{33}$ N. S. Hussein, C. Kost, and T. Schlegh, Electricity Cost from Renewable Energy Technologies in Egypt (Fraunhofer Institut for Solar Energy Systems ISE, 2016).

${ }^{34}$ R. Fu, D. Feldman, R. Margolis, M. Woodhouse, and K. Ardani, U.S. Solar Photovoltaic System Cost Benchmark: Q1 2017 (National Renewable Energy Laboratory NREL, 2017)

${ }^{35}$ J. McLaren, P. Gagnon, K. Anderson, E. Elgqvist, R. Fu, and T. Remo, Battery Energy Storage Market: Commercial Scale, Lithium-Ion Projects in the U.S. (National Renewable Energy Laboratory NREL, 2016).

${ }^{36}$ J. Mayer, S. Philipps, N. S. Hussein, T. Schlegh, and C. Senkpiel, Current and Future Cost of Photovoltaics (Fraunhofer Institut for Solar Energy Systems, ISE, 2015).

${ }^{37}$ International Renewable Energy Agency (IRENA), Battery Storage for Renewables: Market Status and Technology Outlook (IRENA, 2015).

${ }^{38}$ C. Curry, Lithium-Ion Battery Costs and Market: Squeezed Margins Seek Technology Improvements \& New Business Models (Bloomberg New Energy Finance BNEF, 2017).
${ }^{39}$ European Parliament, Energy: New target of 32\% from renewables by 2030 agreed by MEPs and ministers, 19 June 2018.

${ }^{40} \mathrm{~S}$. Cao and K. Sirén, "Impact of simulation time-resolution on the matching of PV production and household electric demand," Appl. Energy 128, 192-208 (2014).

${ }^{41}$ S. Quoilin, K. Kavvadias, A. Mercier, I. Pappone, and A. Zucker, "Quantifying self-consumption linked to solar home battery systems," Appl. Energy 182, 58-67 (2016)

${ }^{42}$ J. Salom, A. J. Marszal, J. Widén, J. Candanedo, and K. B. Lindberg, “Analysis of load match and grid interaction indicators in net zero energy buildings with simulated and monitored data," Appl. Energy 136, 119-131 (2014).

${ }^{43}$ K. Voss, I. Sartori, A. Napolitano, S. Geier et al., "Load matching and grid interaction of net zero energy buildings (IEA SHCP Task40/ECBCS: Towards Net Zero Energy Solar Buildings)," in Eurosun 2010, 29 June (2010).

${ }^{44} \mathrm{~B}$. Burger, www.energy-charts.de for Energy Charts; accessed 22 November 2018.

${ }^{45} \mathrm{M}$. Hukan, "High precision multi-use lithium-ion batteries test-bench for measurement of coulombic efficiency and entropic coefficient," Master thesis (Fraunhofer ISE, 2016).

${ }^{46}$ L. Millet, "Development of an empirically-based numerical model for the BTMS design of an EV's lithium-ion battery pack," thesis for Master of Computational Mechanics, CIMNE (Universitat Politècnica de Catalunya, UPC, 2017). 